\title{
Computational analysis of injection-rate shapes in a small-bore direct-injection diesel engine
}

\author{
V Luckhchoura $^{1 *}$, N Peters ${ }^{1}$, and R Diwakar ${ }^{2}$ \\ ${ }^{1}$ Institut für Technische Verbrennung, RWTH Aachen University, Aachen, Germany \\ ${ }^{2}$ General Motors Research and Development, Warren, Michigan, USA
}

The manuscript was received on 10 September 2009 and was accepted after revision for publication on 5 October 2010.

DOI: $\quad 10.1177 / 1468087410396145$

\begin{abstract}
The purpose of this study is to analyse the differences in the combustion process, and pollutants formation (especially soot) due to top-hat and boot injection-rate shapes at one specific high-load point of a single-cylinder small-bore diesel engine using multidimensional engine simulations. The simulations are performed using a response interactive flamelet model with detailed chemical kinetics. A detailed chemistry-based soot model is used for the prediction of soot emissions. The heights of the first and second stages of the boot shape are varied to observe the effect of the injected fuel mass distribution. In addition, results of boot shapes are compared with a trapezoidal (top-hat) shape. A detailed analysis of soot formation and oxidation is also presented for some selected rate shapes. Through computational analysis it is shown that the boot shapes have the potential to decrease combustion-generated noise and to lower emissions at the investigated load point compared to the top-hat shape. Variations in the temporal distribution of the injected fuel mass show that a lower height of the first stage and a higher height of the second stage of the boot shape result in a relatively slower rise of heat release (lower combustion-generated noise) in the early part of combustion and enhanced soot oxidation as a result of higher spray momentum near the end of injection.
\end{abstract}

Keywords: top-hat, boot, $\mathrm{NO}_{x}$, soot, combustion-generated noise

\section{INTRODUCTION}

In direct injection (DI) diesel engines, the injected spray atomizes rapidly and momentum exchange between vaporized fuel and ambient gas leads to fuel-air mixing. The state of a fuel-air mixture determines the combustion behaviour. Therefore, the control of fuel-air mixing is essential in order to improve combustion efficiency and reduce hazardous emissions such as soot and nitric oxide $\left(\mathrm{NO}_{x}\right)$. Fuel injection-rate shaping is one of the measures that can be used to control fuel-air mixing in the combustion chamber; it results in a specific temporal distribution of fuel for a given injection duration. Injection-rate shaping is known to have the potential

*Corresponding author: Institut für Technische Verbrenung, RWTH Aachen, Templergraben 64, 52056 Aachen, Germany. email:v.luckhchoura@itv.rwth-aachen.de to improve the soot- $\mathrm{NO}_{x}$ trade-off and significantly reduce combustion-generated noise at medium-tohigh -load conditions. Several studies in the literature report on fuel injection-rate shaping and its effects on engine combustion and performance [1-8]. Unlike passenger car engines, the emission limits of heavy-duty engines are strongly related to the high-load operating points. Therefore, most of the fuel injection-rate shaping investigations found in the literature have been performed on heavy-duty engines. Furthermore, packaging constraints in passenger car engines favour the implementation of rate-shaping injection systems in heavy-duty engines. There are two methods to control the temporal distribution of injected fuel with common rail (CR) systems:

(a) control using nozzle needle seat throttling;

(b) control using pressure modulation. 
In the first method, the injection system directly controls the nozzle needle. This concept allows the realization of any partial needle lift between zero and a maximum value. A change in needle lift translates into a change in the seat area. Therefore, the injection-rate shape is controlled by needle seat throttling. In the second method, the injection-rate shape is controlled by changing the injection pressure and keeping the needle completely open.

A research injection system capable of controlling injection-rate shapes by both methods has been designed by the Institute of Technical Combustion at the University of Hannover in order to investigate the effect on the combustion process of diesel engines $[\mathbf{2}, 9-\mathbf{9 1}]$. Optical investigations by Stegemann et al. [12] show that due to throttling and increased cavitation in the case of partial needle lift a stronger disintegration of the spray near the nozzle is achieved, while the resulting spray penetration is reduced. The pressuremodulated injection system results in smaller spray angles and increased penetration. Seebode et al. [13] show a comparison of needle-controlled and pressure-modulated injection-rate shaping and their effects on combustion. Four different injection-rate curves, the standard rectangular, the slow and the fast ramp, and the boot injection were investigated. Their results showed that a boot-type injection shape results in a lower peak pressure due to a leaner premixed fuel-air mixture and a slower heat release at the beginning of combustion, and also a later phasing of combustion. This results in a significant reduction in $\mathrm{NO}_{x}$ emissions. Compared to the pressure-modulated injection (decreased entrainment of cylinder charge, higher local fuel-air ratios), needle-controlled injection produces increased soot emissions and fuel consumption. Therefore, better results can be achieved if the injection rate is a function of the injection pressure and if the needle opens as fast as possible to avoid throttling effects.

Tanabe et al. [5] proposed a map to identify optimum injection-rate shapes (through pressure modulation) across the engine speed and load range of a heavy-duty DI diesel engine, indicating the optimum injection-rate shape for each operating region. In the low-load region, a square rate shape should be used, whereas in the high-load region a boot shape should be preferred until the engine speed reaches the medium speed region. As the engine speed increases, the best approach is to transition through the ramp rate-shape and back to a square rate-shape. Tanabe et al. [5] also investigated the effect of rate shaping under exhaust gas recirculation (EGR) conditions. Their results showed that in the operating region where the $\mathrm{NO}_{x}$-fuel consumption trade-off was improved by injection rate-shape control the effect of rate-shape control was independent of EGR levels. Thus, it was concluded that EGR and injection-rate shaping could be independently used as engine control parameters.

Kastner et al. [7] evaluated multiple-injection strategies and injection-rate shaping in a singlecylinder research engine to meet Euro-6 legislation limits at two part-load points: $1500 \mathrm{rpm} / 4.2 \mathrm{bar}$ indicated mean effective pressure (IMEP) and $2280 \mathrm{rpm} / 10.5$ bar IMEP. Injection-rate shapes were controlled by nozzle-needle throttling. Boot injection at a high-load point improved the soot$\mathrm{NO}_{x}$ trade-off in comparison to the conventional multiple-injection pattern.

The present study is based on a pressuremodulated rate-shaping injector, the so-called common rail rate shaping (CoraRS). Previously, Rottmann et al. [14] investigated the effect of injection-rate shapes on engine performance and emissions at two load points. Their results showed improvement in engine performance due to rate shapes, with boot shapes showing the overall best performance. Engine simulations using the multidimensional flow solver AC-FluX (formerly known as GMTEC) with a representative interactive flamelet (RIF) combustion model have also been performed to capture the effects of different injection-rate shapes $[14,15]$. Comparing simulation results and trends with experimental results, it can be concluded that the model results can capture the effects caused by different injection-rate shapes (such as its the heat release pattern and the soot$\mathrm{NO}_{x}$ trade-off). This point provides confidence in the capabilities of the computational fluid dynamics (CFD) model to simulate the complex phenomena in diesel engines. Although the earlier experimental investigation [14] on rate shapes showed the global affect on engine performance, the detailed timedependent effects of injection rate shaping could not be captured in such experiments. Since injection-rate shaping is, in effect, a temporal change in the injected fuel mass, it is necessary to understand and explain the global results by investigating the transient behaviour of spray, combustion, and pollutant formation. Results from threedimensional CFD engine simulations could allow an understanding of the underlying differences caused by different rate shapes to be obtained. Although the fuelling and EGR levels vary in experiments to maintain constant IMEP and $\mathrm{NO}_{x}$, it is rather difficult in simulations to maintain such constraints. Also, varying the EGR levels also affects the 
combustion and pollutant chemistry. Therefore, in the present computations, the initial and boundary conditions are kept constant without imposing any constraint on the engine-out quantities. In the present study, the boot injection-rate shape consists of two stages (see Fig. 1): the first stage until the end of time $t_{1}$ and the second stage between times $t_{1}$ and $t_{2}$. In the first stage, the injection rate increases linearly from zero to $h_{1}$ and remains constant till the end of time $t_{1}$. In the second stage, the injection rate increases linearly from $h_{1}$ to $h_{2}$ followed by a constant injection rate of $h_{2}$, and then it decreases linearly to zero at the end of time $t_{2}$. The maximum injection rate (referred to as height in the present study) in both stages of the boot injection-rate shape is the parameter of variation in the present study. At constant injected fuel mass and constant overall injection duration, the following variations are performed in the computational study.

1. The height in the first stage, $h_{1}$, is varied by adjusting the time ratio $t_{2} / t_{1}$. The height in the second stage remains the same. Hence, the injected fuel mass in the first stage also varies with the change in height, as shown in Fig. 1.

2. Height in the second stage, $h_{2}$, is varied by adjusting the time ratio $t_{2} / t_{1}$. The height in the first stage remains the same. The ratio of the injected fuel mass of both stages varies a little, as shown in Fig. 1.

An analysis of different rate shapes is done at one specific engine operating point. This study is by no means intended to be an optimization of the boot

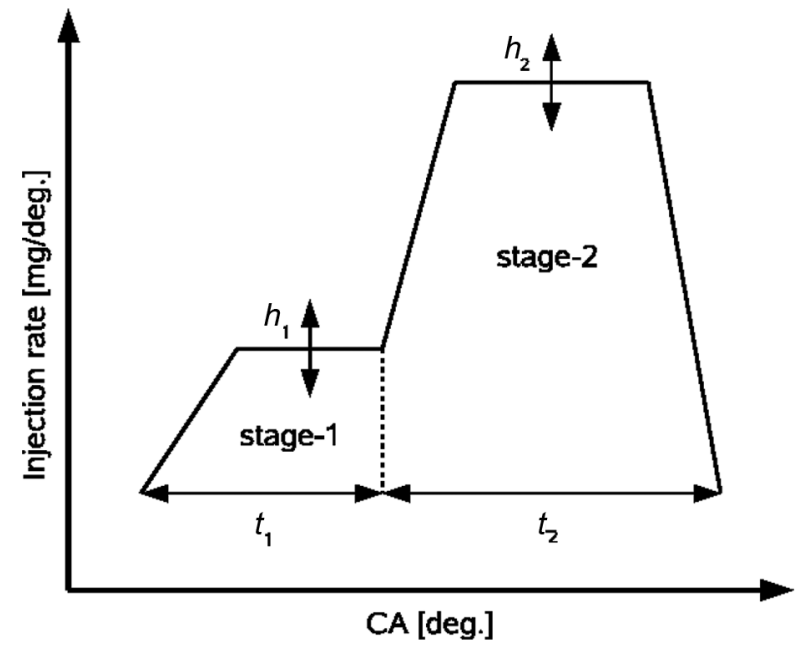

Fig. 1 Boot injection rate shape, height variation of the stages of the boot shape are also shown injection-rate; rather, it is aimed at casting some light onto the problem by a detailed modelling of the evolution of the in-cylinder changes in fuel-air mixtures caused by different rate shapes and the subsequent ignition, combustion, and pollutant formation.

\section{COMPUTATIONAL MODEL}

The RIF model has been extensively described and applied over the years for three-dimensional engine simulations [16-21]. Therefore, it is explained only briefly here. The schematic flow diagram in Fig. 2 shows the interaction of the CFD and Flamelet codes.

\subsection{Flamelet model}

The flamelet concept views a turbulent flame as an ensemble of flamelet structures, attached to the instantaneous position of the flame surface, which itself is corrugated by the turbulent flow field. The flamelet structure may be computed based on unsteady diffusive-reactive equations using a separate flamelet code. The flame structure is onedimensional. The mass fractions and the temperature are assumed to be uniquely related to the mixture fraction $Z$, which is the independent variable in the so-called flamelet equations. The outer flow field imposes a conditioned scalar dissipation rate on the flame structure. For a turbulent flow field this is replaced by their conditional mean values and, the mass fractions and the temperature may be interpreted as mean quantities conditioned on mixture fraction.

\subsection{The pre-assumed shape probability distribu- tion function approach}

Once the dependence of the reactive scalars on $Z$ is calculated by the flamelet code, turbulent mean quantities can be calculated, if the respective probability distribution function (PDF) is known. Girimaji [22] has shown that the $\beta$-PDF shape is appropriate for capturing the nature of the relevant mixing processes in non-premixed combustion. Its functional form is pre-assumed and its local shape is fixed at each point of the flow field by relating to the two known parameters: mean mixture fraction $(\widetilde{Z})$ and variance $\left(\widetilde{Z}^{\prime \prime 2}\right)$ of mixture fraction. The $\beta$-PDF has the form

$$
\widetilde{P}(Z ; x, t)=\frac{Z^{\alpha-1}(1-Z)^{\beta-1}}{\Gamma(\alpha) \Gamma(\beta)} \Gamma(\alpha+\beta)
$$




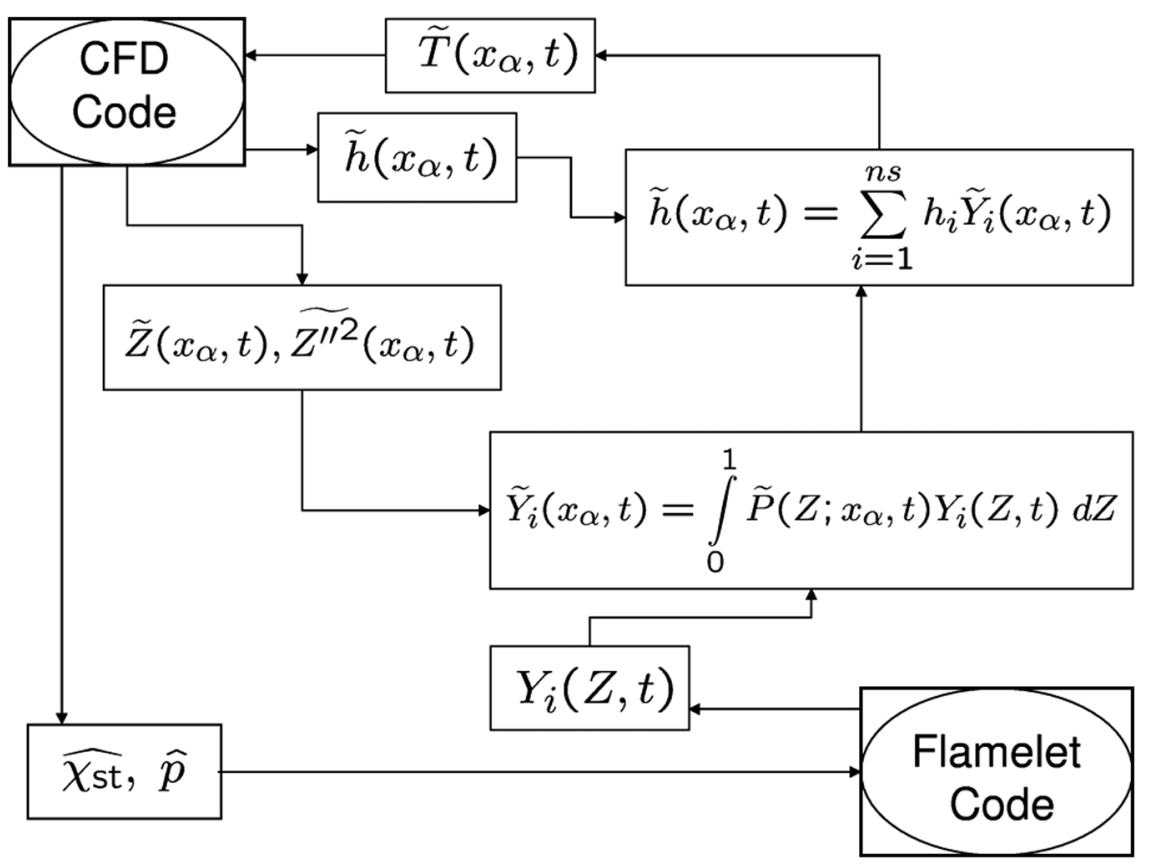

Fig. 2 Code structure of the RIF model

where $x$ is space, $t$ is time, and $\Gamma$ is the gamma function. The two parameters $\alpha$ and $\beta$ are related to the mean and variance of the mixture fraction by

$$
\widetilde{\alpha}=\widetilde{Z} \gamma, \quad \beta=(1-\widetilde{Z}) \gamma
$$

where

$$
\gamma=\frac{\widetilde{Z}(1-\widetilde{Z})}{\widetilde{Z}^{\prime 2}}-1 \geq 0
$$

It can be shown from equation (1) that in the limit of very small $\widetilde{Z}^{\prime \prime 2}$ (large $\gamma$ ), the $\beta$-PDF approaches a Gaussian distribution. For $\alpha<1$ it develops a singularity at $Z=0$ and for $\beta<1$ a singularity at $Z=1$.

\subsection{CFD code}

The main advantage of the flamelet concept is the fact that the chemical reaction time and length scales need not be resolved in a multidimensional CFD code. In addition to the continuity, momentum, and energy equations, equations describing turbulence quantities such as the turbulent kinetic energy and its dissipation rate are solved, and thereby the turbulent length and time scales can be evaluated. In addition to that, the balance equations for the mean and variance of the mixture fraction describing the mixing field need to be solved numerically. The flamelet solution provides all scalars as a function of the mixture fraction at each time step. Turbulent mean values of these scalars in each direction $\alpha$ are then obtained by integrating their flamelet solutions with the pre-assumed shape PDF in each CFD cell

$$
\widetilde{Y}_{i}\left(x_{\alpha}, t\right)=\int_{Z=0}^{1} \widetilde{P}\left(Z ; x_{\alpha}, t\right) Y_{i}(Z, t) d Z
$$

where, $Y_{i}$ represents the species mass fraction. For the present work, the multidimensional CFD computer code AC-FluX was used, which is based on finite volume methods that employ unstructured, mostly hexahedral meshes. AC-FluX has been documented in detail by Ewald et al. [23].

\subsection{Spray model}

Solving the dynamics of a spray with a wide distribution of drop sizes, velocities, and temperatures is a complicated problem. A mathematical formulation capable of describing this distribution is the spray equation proposed by Williams [24]. It is an evolution equation for the probability density function $f$, with the independent variables being the droplet position, droplet velocity, temperature, radius, distortion from sphericity $y$, and its time derivative $d y / d t$. Depending on the specific problem, additional variables can be introduced. A direct solution of this equation is extremely difficult due to its high dimensionality; the aforementioned 
variables alone constitute a ten-dimensional space and the associated storage and computing time requirements. Instead, a sufficiently large number of particles, which, following Crowe et al. [25], are called parcels in the following, are introduced. This model is usually referred to as the discrete droplet model. Each parcel represents an ensemble of droplets. Within one parcel all droplets have the same properties, which correspond to the previously described independent variables. The ensemble of all parcels provides statistical information on the spray. Important processes which need to be described are break-up, collision, coalescence, evaporation, and dispersion. A detailed description of the models for these processes and the formulation of source terms for the gas phase equations can be found in [26], with the exception of the break-up model which can be found in reference [27].

\subsection{Surrogate fuel}

A major aspect in modelling diesel engine combustion is the treatment of the combustion chemistry. Diesel fuel is a mixture of several hundreds to thousands of different hydrocarbon species differing in size and structure, ranging from small aliphatic to large aromatic components. The exact composition may differ depending on the refining at which the fuel was produced. Developing a chemical kinetics mechanism that can account for the exact composition is therefore neither possible nor feasible, and formulating chemical mechanisms for surrogate fuels with a limited number of components is the only realistic option. An important aspect of such a surrogate fuel is that it can accurately reproduce the auto-ignition aspects, which are important characteristics of diesel engine combustion. Within the IDEA-EFFECT program, a mixture of 70 per cent n-decane and 30 per cent $\alpha$-methylnaphthalene (liquid volume), the so-called IDEA fuel, has been thoroughly investigated. The density, cetane number, and carbon-to-hydrogen ratio of diesel fuel are very similar to the IDEA fuel. Antoni [28] used both fuels for experiments in a Volkswagen DI diesel engine. Measured ignition and heat release characteristics were almost identical for both fuels, confirming the similarity of their physical and chemical properties. In addition to measuring the cylinder pressures, pollutant emission measurements were also carried out. Measured $\mathrm{NO}_{x}$ and soot emissions were also similar; however, the IDEA fuel yielded slightly lower amounts with a maximum deviation of 7 per cent for $\mathrm{NO}_{x}$ and 30 per cent for soot. The complete chemical reaction mechanism for the IDEA fuel comprises 519 elementary reactions and 109 chemical species [29]. This mechanism describes low and high-temperature autoignition and combustion, as well as the formation of soot precursors and $\mathrm{NO}_{x}$.

\section{6 $\mathrm{NO}_{x}$ and soot models}

The $\mathrm{NO}_{x}$ mechanism used in the current study was developed by Bollig [30] and is a part of the IDEA mechanism. The mechanism accounts for thermal, prompt, and nitrous oxide contributions to $\mathrm{NO}_{x}$ formation, and for $\mathrm{NO}_{x}$ reburn by hydrocarbon radicals and amines $\left(\mathrm{NH}_{x}\right)$. Generally, thermal NO (often referred to as Zeldovich-NO) is by far the most significant contribution to in-cylinder $\mathrm{NO}_{x}$ in a diesel engine. Reverse Zeldovich is the most important mechanism in reducing $\mathrm{NO}_{x}$ in the postflame oxidation process. However, if the temperature is too low, the $\mathrm{NO}_{x}$ chemistry becomes subject to a state denoted as frozen equilibrium. This refers to a situation where $\mathrm{NO}_{x}$ exists in proportions far above those given by the chemical equilibrium at the prevailing temperature. The reverse reactions are too slow to drive the concentration towards the equilibrium. Prompt NO (sometimes referred to as Fennimore-NO) becomes important when the residence time in hot regions gets shorter, as suggested by its name. The reburn-NO mechanism has to be considered under conditions of strong thermal NO formation. Hence, models that only consider the thermal path tend to over predict NO under conditions where prompt NO plays a minor role.

Soot emissions were predicted using a detailed chemistry-based soot model. Soot precursor chemistry is described up to benzene (first aromatic ring). Further formation and growth of small polycyclic aromatic hydrocarbons (PAHs) is included in the IDEA mechanism up to PAHs consisting of four aromatic rings. The first soot particles are formed when two PAHs coagulate. This is called particle inception. The formation, growth, and oxidation of soot particles is described by a kinetics-based model. A method using statistical moments is employed [31, 32] to solve the size distribution of the soot particles. Two statistical moments are solved: the zeroth statistical moment yields the soot particle number density of all sizes, the first statistical moment is proportional to the soot volume fraction.

\section{EXPERIMENTAL SETUP}

Experiments were carried out in a $0.45 \mathrm{l}$ singlecylinder test engine whose specifications are 
Table 1 Main characteristics of the one-cylinder engine

\begin{tabular}{ll}
\hline Swept volume & $450 \mathrm{~cm}^{3}$ \\
Stroke & $88 \mathrm{~mm}$ \\
Bore & $81 \mathrm{~mm}$ \\
Compression ratio & 16.10 \\
Swirl & 1.7 \\
High-pressure pump & Bosch CP \\
Rail & Bosch \\
Injector & CoraRS \\
Cone angle & $158^{\circ}$ \\
Design & Mini-sac \\
Hydraulic flowrate & $450 \mathrm{~cm}^{3} / 30 \mathrm{~s}$ \\
Hole diameter & $0.143 \mathrm{~mm}$ \\
Hole numbers & 7 \\
Nozzle $k$-factor & 1.5 \\
\hline
\end{tabular}

Table 2 Operating point of one-cylinder engine

\begin{tabular}{ll}
\hline Engine speed & $2400 \mathrm{rpm}$ \\
Injection-rate shapes & Top-hat and Boot \\
SOI, EOI* & $-2.0^{\circ}, 19.8^{\circ}$ ATDC \\
Injected fuel mass & $38.15 \mathrm{mg}$ \\
EGR & $27.85 \%$ \\
\hline
\end{tabular}

*SOI, start of ignition; EOI, end of ignition.

summarized in Table 1. The injection system consisted of a Bosch common rail system and CoraRS injector. A seven-hole mini-sac orifice nozzle with a hydraulic mass-flowrate of $450 \mathrm{~cm}^{3}$ per $30 \mathrm{~s}$, a spray angle of $158^{\circ}$, and a $k$-factor of 1.5 was mounted on the injector. The $k$-factor is a measure for the conicity of the orifice, where a positive $\mathrm{k}$-factor means that the orifice narrows towards the exit of the nozzle. A measured rate shape with the CoraRS injector was used for generating different injection-rate shapes. Further details on the experimental setup and on the injection system are given in [14]. Data pertaining to an engine operating point, for which simulations were performed, is used in Table 2.

\section{SIMULATION APPROACH}

A sector mesh representing one-seventh of the combustion chamber could be used for the CFD simulations, by taking advantage of the circumferential symmetry of the centrally located injector equipped with a seven-hole nozzle. The computations started from intake valve closure (IVC) at $118^{\circ}$ ATDC (after top dead centre) and ended at exhaust valve open (EVO) at $+120^{\circ}$ ATDC. Quantities such as trapped mass, intake pressure, and temperature of the EGR were all obtained from experimental data.

The piston movement in the compression and expansion strokes changes the distance between the

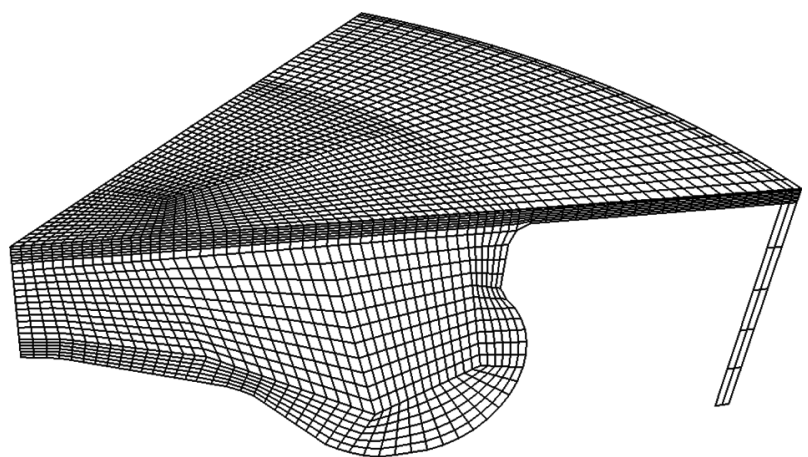

Fig. 3 Computational mesh of a single-cylinder diesel engine at TDC, the cylinder head and walls have been removed for clarity

cylinder head and piston crown. Varying the distance would require a change in the number of cells between the piston crown and cylinder head region to ensure sufficient spatial resolution, and a lower computational time when simulating flow and mixing fields. For instance, when the piston is near top dead centre (TDC) fewer cells are required compared to when the piston is moving away from TDC (in the expansion stroke). Due to computational issues, in the present study the number of cells within the region remains constant with the moving piston. A single computational mesh would not be able to maintain sufficient spatial resolution and an acceptable computing time throughout the entire engine cycle. Therefore, seven different computational meshes were used during the simulation of the piston movement from IVC to EVO. A remap of solutions was done before switching between different meshes. The computational mesh at TDC is shown in Fig. 3.

\section{RESULTS AND DISCUSSION}

To begin the numerical analysis of boot injectionrate shapes, a representative shape of the boot injection was obtained by interpolating the measured rate [14], as shown in Fig. 4. The height variation of the first stage of the boot injection-rate shape (see Fig. 1) is referred to as $\mathrm{SCl}$, and the rate shapes in SCl are named from A to $\mathrm{H}$. Computed results are analysed and discussed for all the rate shapes in SCl and for the top-hat shape. Cylinder pressure, heat release rate, emissions at EVO, representative (Rep.) IMEP, and ringing intensity (representative of combustion-generated noise) are the key global parameters extracted from the results of each simulation. The Rep. IMEP and ringing intensity $(R I)$ can be defined as 


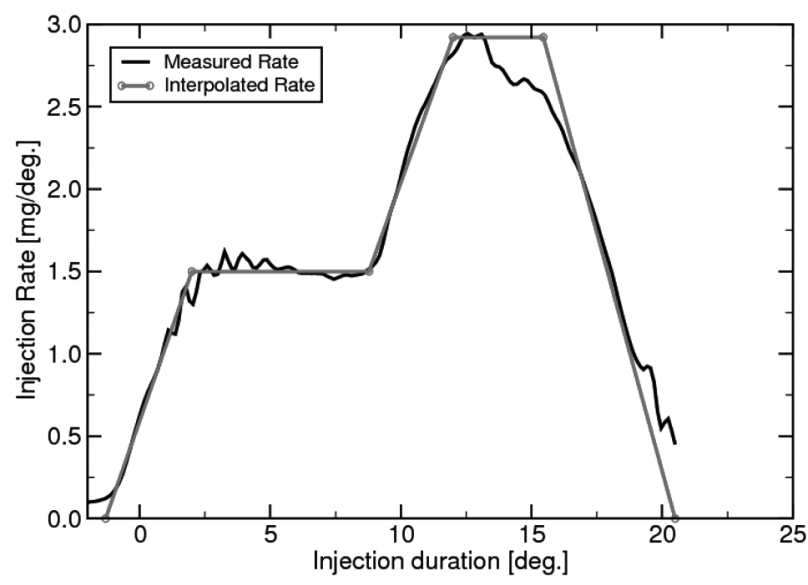

Fig. 4 Measured and interpolated boot injection-rate shapes, the interpolated rate shape was used to generate different boot shapes in this study

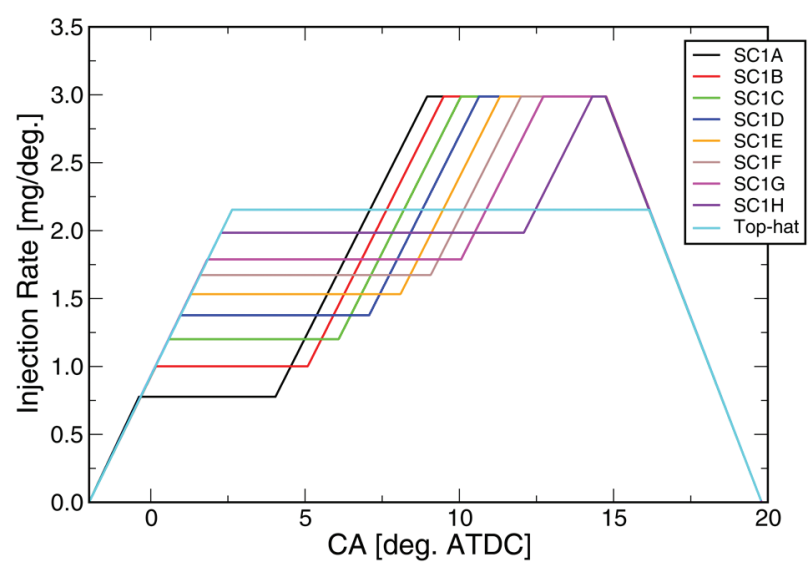

Fig. 5 Fuel injection rate profile of different rate shapes in variation-1

$$
\begin{aligned}
& \text { Rep.IMEP }=\frac{\int_{I V C}^{E V O} p d v}{\int_{I V C}^{T D C} d v} \\
& R I \approx \frac{1}{2 \gamma} \frac{\left(\beta(d p / d t)_{\max }\right)^{2}}{p} \sqrt{\gamma R T}
\end{aligned}
$$

Rep.IMEP in equation (5) (expressed in bar) represents the work done between IVC and EVO normalized by the displacement volume between IVC and TDC. In order to quantify the combustion noise levels in the simulations, the ringing intensity correlation developed by Eng [33] was applied. This correlation relates the ringing intensity to the maximum pressure rise rate, maximum cylinder pressure, and speed of sound. In equation (6), $\beta$ is a scale factor, $(d p / d t)_{\max }$ is the maximum rate of pressure rise $(\mathrm{kPa} / \mathrm{ms}), p$ is the mean cylinder pressure $(\mathrm{kPa}), T$ is the mean cylinder temperature $(\mathrm{K})$, and $R I$ is calculated in Megawatts per square metre.

\subsection{Boot injection rate: variation-1 (SC1)}

In this section, a variation in the boot height of the first stage ( $h_{1}$ in Fig. 1$)$ is investigated. The height of the first stage was varied by adjusting the time ratio $t_{2} / t_{1}$, while the boot height of the second stage $\left(h_{2}\right.$ in Fig. 1) was kept constant. The total injected fuel mass and overall injection duration were constant for all rate shapes. Simulations were performed for all boot injection-rate shapes, SC1A to SC1H, and for the top-hat shaped injection rate, as shown in Fig. 5 as a function of the crank angle (CA). Figure 6 shows the injected fuel mass, as a percentage of total fuel mass, in the first stage. Injected fuel mass in the first stage varies almost linearly with rate shapes from SC1A to SC1H. In SC1A (lowest boot height in the first stage) 11 per cent of the total fuel mass is injected; and in $\mathrm{SC1H}$ (highest boot height in the first stage) 63 per cent of the total fuel mass is injected. Figure 7 shows normalized cumulative injected fuel mass (in per cent) as a function of CA. For SC1A, SC1H, and top-hat shapes. Their corresponding cumulative spray momentum is shown in Fig. 8. The total spray momentum at the end of the injection has its highest value for SC1A and is almost equal for the $\mathrm{SC} 1 \mathrm{H}$ and top-hat shapes. Compared with SC1A, 56 per cent of the total fuel mass in $\mathrm{SC} 1 \mathrm{H}$ is injected with a higher spray momentum, and 68 per cent of the total injected fuel mass in the top-hat shape has a higher spray momentum. Compared to $\mathrm{SC} 1 \mathrm{H}, 83$ per cent of the total injected fuel mass in the top-hat shape has a higher spray momentum. It is well known that the mixing process is heavily influenced by spray momentum, i.e. the higher the spray momentum, the higher is the mixing level.

In the following two subsections, cylinderaveraged results and a detailed analysis of soot formation and oxidation are presented. Trends of global results are shown for all simulated rate shapes in variation-1. From the obtained results, a monotonic behaviour with the boot height of the first stage was found for all boot rate shapes. Since SC1A and $\mathrm{SC1H}$ are two extreme rate shapes in variation-1, their results along with the results for the top-hat shape are compared to explain trends, where necessary.

\subsubsection{Global results}

Figure 9 shows the fuel evaporation rate as a function of CA in SC1A, SC1H, and the top-hat shape. 


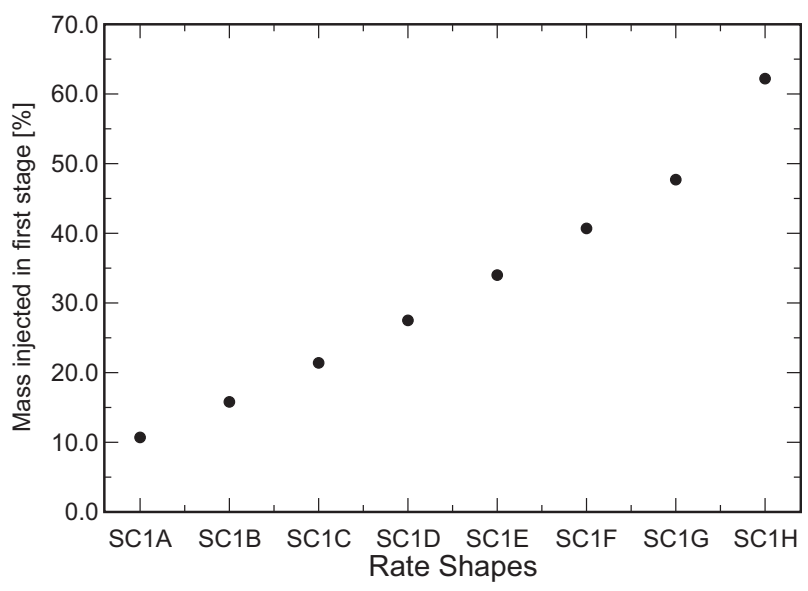

Fig. 6 Injected fuel mass in the first stage of the boot injection-rate shape, shown as a percentage of overall total injected fuel mass

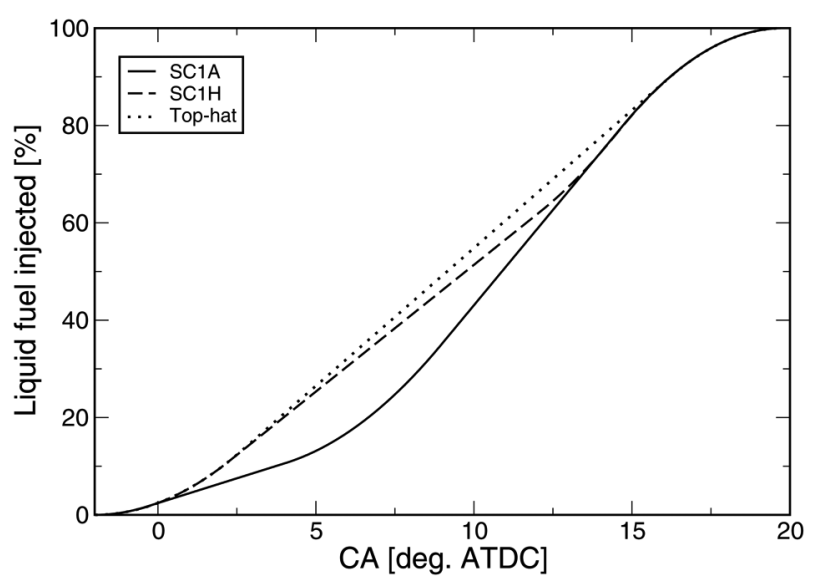

Fig. 7 Comparison of the normalized cumulative injected fuel mass in the SC1A, SC1H, and tophat rate shapes

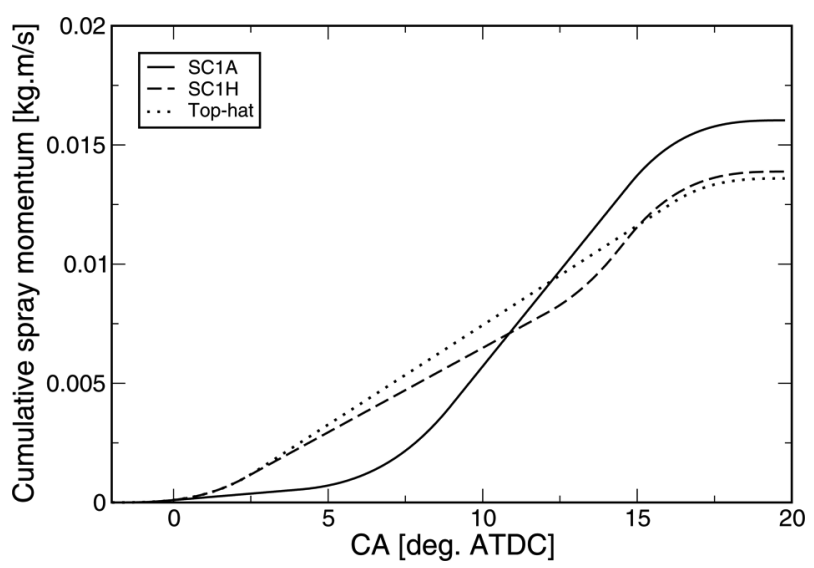

Fig. 8 Comparison of the cumulative spray momentum in the SC1A, SC1H, and top-hat rate shapes

For a comparison among the rate shapes, evaporation rates can be divided into three parts: the first part up to $7^{\circ}$ ATDC, the second part between $7^{\circ}$ and

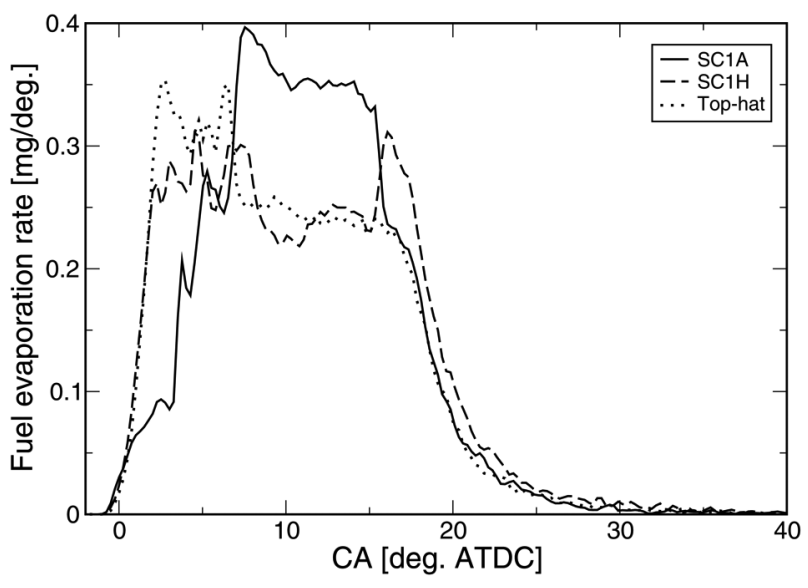

Fig. 9 Evaporated fuel mass as a function of CA in the $\mathrm{SC} 1 \mathrm{~A}, \mathrm{SC} 1 \mathrm{H}$, and top-hat rate shapes

$16^{\circ}$ ATDC, and the third part is after $16^{\circ}$ ATDC. In part 1 , the evaporation rate in the top-hat shape has already reached its maximum and has the highest level among the rate shapes (similar to injection-rate profiles). In part 2, the evaporation rate in SC1A achieves its maximum, and in the tophat shape's evaporation has become quasi-steady. Due to the increase in injection rate after $12.5^{\circ}$ ATDC in $\mathrm{SC1H}$, the corresponding evaporation rate starts to rise again. After $16^{\circ}$ ATDC (part 3), a second peak in the evaporation rate of $\mathrm{SC} 1 \mathrm{H}$ is seen. This could be the catching up of the evaporation of the poorly atomized part of the injected fuel in part 2. Later in part 3, the evaporation rate for all three rate shapes decays. Therefore, it can be concluded that the trend of the evaporation rate in all three rate shapes follows their injection profile.

In Fig. 10, cylinder pressure variations as a function of CA are shown for different injection-rate shapes (see Fig. 5). The injection event (duration) is also indicated in the figure. As previously mentioned, injection started at $-2^{\circ}$ ATDC and ended at $19.8^{\circ}$ ATDC. Among all rate shapes, the top-hat shape resulted in the maximum peak cylinder pressure. This could be associated with the evaporation rates in part 1 (Fig. 9). The increase of fuel mass in the first stage tends to increase the cylinder pressure after the onset of ignition (similar to the trend in evaporation rate for all rate shapes in part 1 in Fig. 9). In rate shapes where up to 30 per cent of the total fuel mass is injected in the first stage, the peak cylinder pressure occurs later in the expansion stroke (akin to the evaporation rate for all rate shapes in parts 2 and 3 in Fig. 9). Overall, a reduction of 8.0 bar for the peak cylinder pressure is predicted by lowering the injected fuel mass in the first stage of the boot shape. 


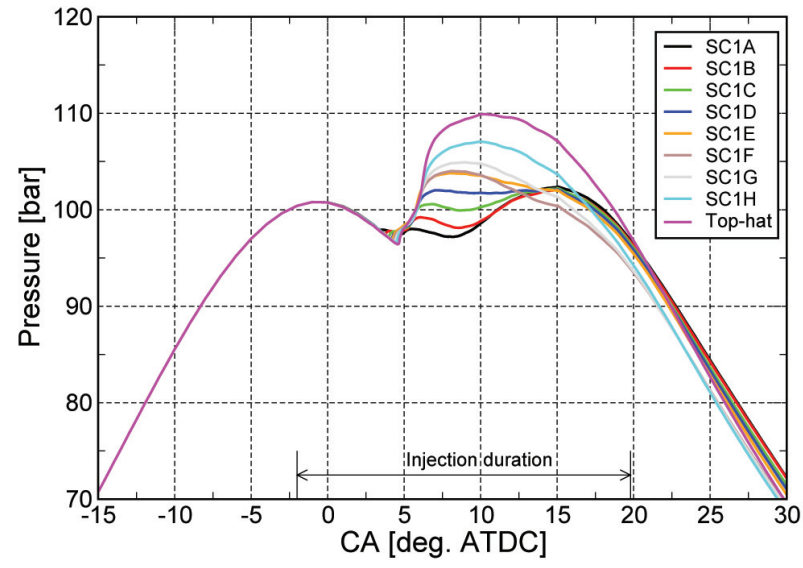

Fig. 10 Comparison of simulated cylinder pressure

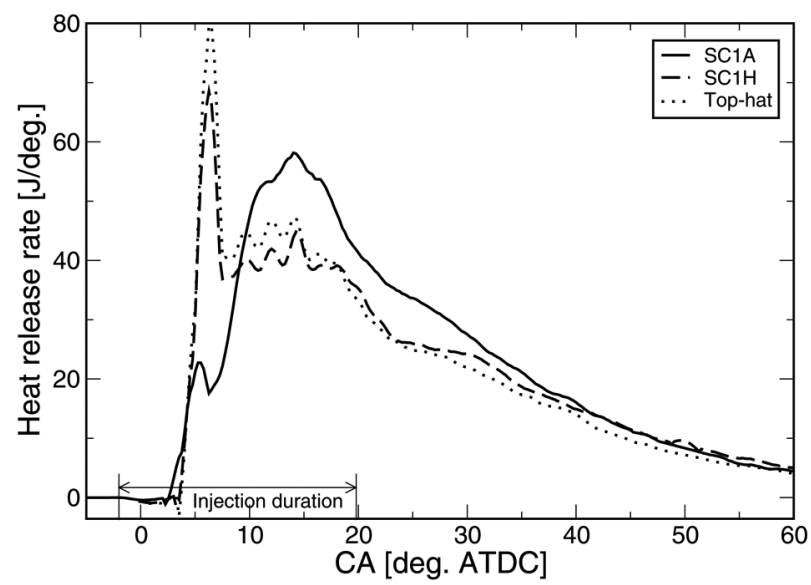

Fig. 11 Comparison of the calculated heat release rates in the SC1A, SC1H, and top-hat shapes

Heat-release rate profiles are compared in Fig. 11. For the sake of clarity, profiles are shown and discussed only for three injection-rate shapes (SC1A, SC1H, and top-hat). The effect of the initial injection rate is evident from the premixed spike of the heat release rate (Fig. 11). The top-hat shape shows the highest premixed spike in the heat release rate, whereas the shape with the lowest boot height (SC1A) shows the lowest premixed spike. Interestingly, the increasing order of the premixed spikes of the heat release rates resembles the order of the peaks of the evaporation rates, as shown in part 1 (until $7^{\circ}$ ATDC in Fig. 9) for corresponding rate shapes. A comparison of diffusion-controlled combustion (after the premixed spike in Fig. 11) shows that the increased fuel mass in the second stage results in higher rates of heat release (compare SC1A to SC1H). The weak correspondence between evaporation rate (parts 2 and 3 in Fig. 9)

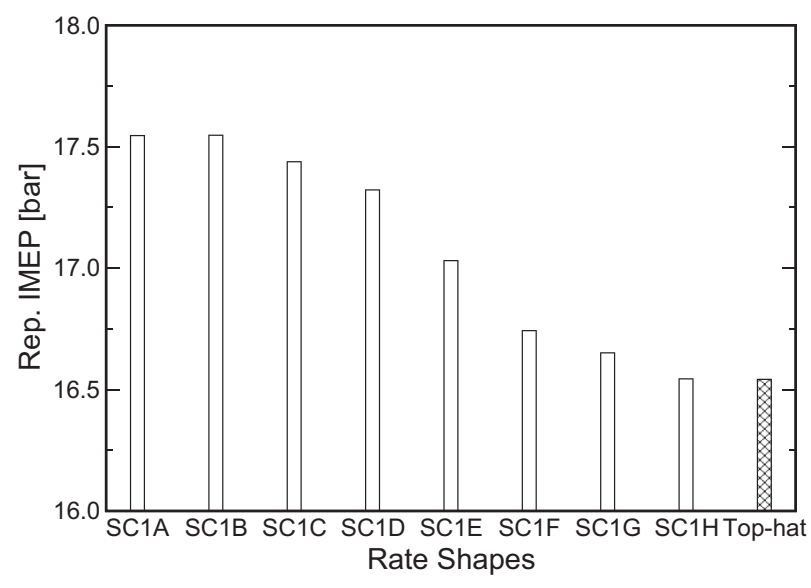

Fig. 12 Comparison of Rep. IMEP for different rate shapes in variation-1

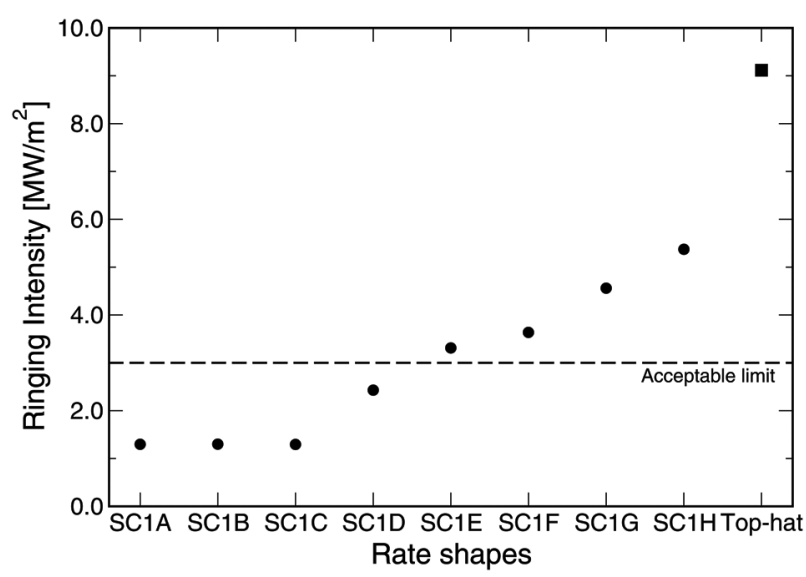

Fig. 13 Comparison of the ringing intensity (quantitative indicator of combustion-generated noise) for different rate shapes in variation-1

and heat release rate at later CAs is due to the diffusion (or mixing) -controlled combustion phase.

The influence of different rate shapes on Rep. IMEP is shown in Fig. 12. In the figure, lowering the boot height of the first stage creates a monotonic increase in Rep. IMEP. For SC1A, a 6 per cent improvement in Rep. IMEP in comparison to the top-hat shape confirms the potential of rateshaping on fuel economy.

Ringing intensity (see equation (6)), a quantitative indicator of combustion-generated noise, is shown in Fig. 13 for different injection-rate shapes. The horizontal dashed line in Fig. 13 represents an acceptable noise limit (R.M. Siewert, 2008, Personal Communication) for the investigated single-cylinder engine (see Table 1). Combustion-generated noise is controlled by the early part of the combustion process, with the initial rapid heat release immediately following the ignition delay. Due to significant 


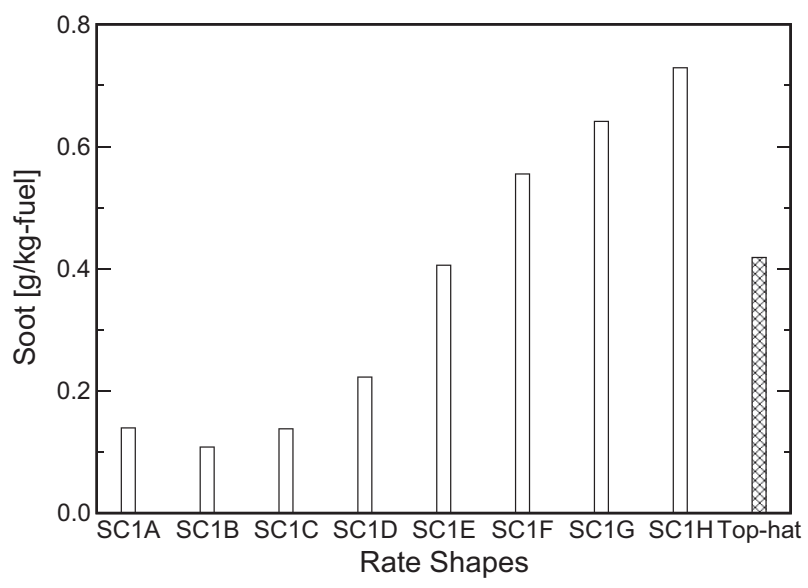

Fig. 14 Trend in soot emissions at EVO with varying boot heights of the first stage in variation-1

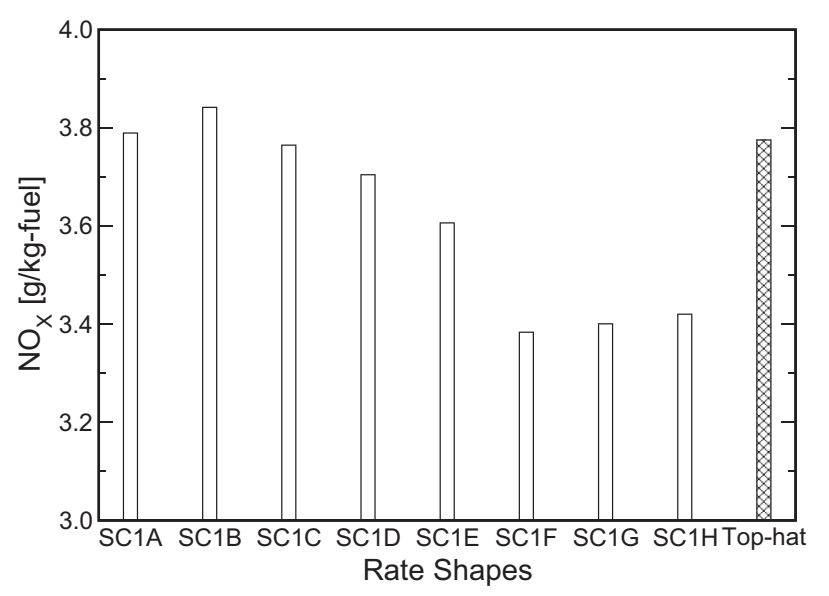

Fig. $15 \mathrm{NO}_{x}$ emissions at EVO for different rate shapes in variation-1

changes in the initial heat release among the rate shapes, as shown in Fig. 11, a variation in the ringing intensity is reasonable. Ringing intensity comparisons show that rate shapes SC1A to SC1D fall under the acceptable noise limit. When compared with the injection rate of the top-hat shape the ringing intensity in SC1A decreases by a factor of 7.5. It can be concluded that lowering the boot height of the first stage is favourable in reducing combustion-generated noise.

Rottmann et al. [14] compared the top-hat, tophat with pilot injection, and boot-shaped rates in a small-bore DI diesel engine. Their results showed that top-hat with pilot injection can achieve similar combustion-noise levels as for the case of the bootshaped rate. However, the boot-shaped rate offered the best soot- $\mathrm{NO}_{x}$ trade-off. Additionally, it can also be expected that adding a pilot to the boot-shaped rate would also lead to further reduction in combustion-generated noise.

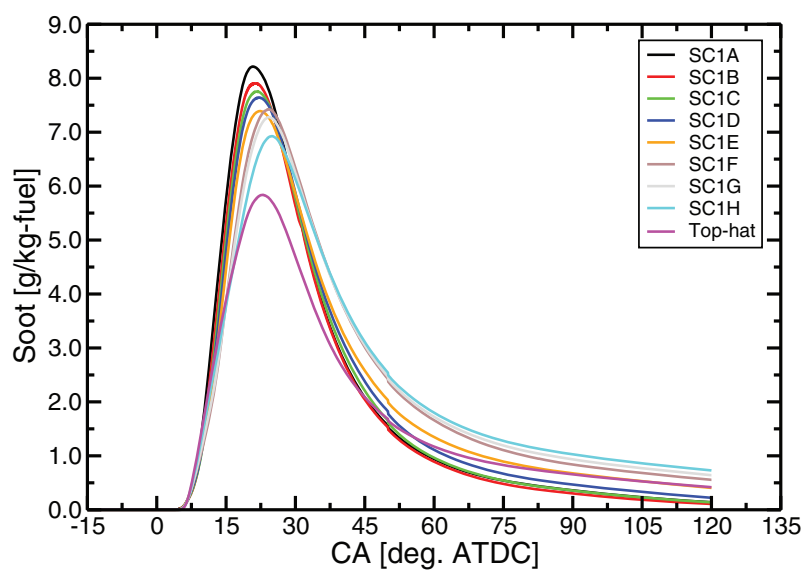

Fig. 16 Net in-cylinder amount of soot as a function of CA for different rate shapes in variation-1

Net in-cylinder soot at EVO for different injection-rate shapes is shown in Fig. 14. Net incylinder soot is expressed as grams per kilogram of fuel. This figure indicates that some of the boot shapes are not favourable for soot reduction in comparison to the top-hat shape. It is also evident that by lowering the boot height of the first stage a reduction in soot could be achieved. The rate shape with the lowest boot height in the first stage (SC1A) predicts the lowest soot at EVO, and SC1H (the shape with the highest boot height in the second stage) predicts the highest soot at EVO.

$\mathrm{NO}_{x}$ emission values (expressed as grams per kilogram of fuel), which are the sum of both NO and $\mathrm{NO}_{2}$, are shown in Fig. 15 for all injection-rate shapes in variation-1. This figure shows their values at EVO. It can be seen in Fig. 15 that an increase in the boot height of the first stage is advantageous for $\mathrm{NO}_{x}$ emission reduction at EVO, whereas decreasing the boot height in the first stage shows no significant change in $\mathrm{NO}_{x}$ emissions when compared with the top-hat injection at EVO. $\mathrm{NO}_{x}$ emissions are very sensitive to changes in EGR and SOI. Since the SOI and EGR per cent are not changed for the different rate shapes, it is not surprising to see only small changes in $\mathrm{NO}_{x}$ in Fig. 15.

\subsubsection{Detailed analysis of soot formation and oxidation}

Net in-cylinder soot level is a result of soot formation and oxidation. CA variation of net in-cylinder soot, shown in Fig. 16, elucidates the effect of boot height. Peak soot for different injection-rate shapes is a monotonic function of the boot height of the first stage, i.e. the peak soot level increases with decreasing boot height of the first stage. In addition, the location of the peak soot level retards with 


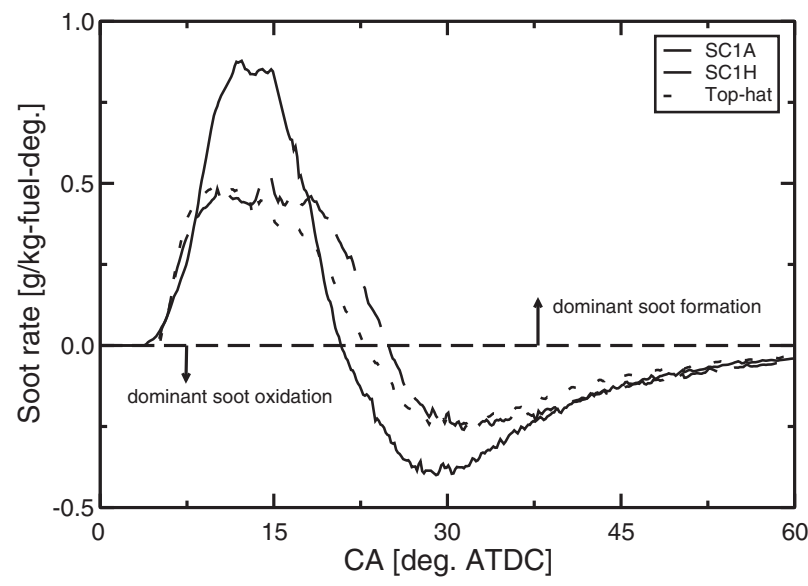

Fig. 17 Net soot rate (time derivative of net incylinder soot) for the SC1A, SC1H, and tophat shapes in variation-1

increasing boot height of the first stage. The peak value of the amount of soot is highest for SC1A and lowest for the top-hat shape. Figure 17 shows the net soot rate, which is a temporal gradient of net in-cylinder soot, for three injection-rate shapes. A positive soot rate indicates the dominance of soot formation and a negative soot rate indicates the dominance of soot oxidation [34]. The high soot formation rates for SC1A in Fig. 17 result in the highest peak soot value among all rate shapes. However, soot oxidation rates are also high for this shape, resulting in the lowest net soot level at EVO. As the height of the first stage is increased to its highest level in $\mathrm{SClH}$, both soot formation and oxidation rates decrease, resulting in the highest net soot level at EVO among all rate shapes. For top-hat shape, soot formation and oxidation rates are such that the net soot level at EVO is higher than in SC1A, but lower than in SC1H.

It is evident from the previous discussion that soot formation and oxidation are equally important to achieve a reduction of net soot level in the exhaust. It is well known that acetylene $\left(\mathrm{C}_{2} \mathrm{H}_{2}\right)$ is primarily responsible for soot growth after soot nucleation, and hydroxyl $(\mathrm{OH})$ radicals oxidize the soot particles. In the following, the details of soot formation and oxidation are analysed for the SC1A and $\mathrm{SC} 1 \mathrm{H}$ rate shapes. For this purpose, the flow field and soot isovolumes are studied at the CAs which are in the proximity of the peak rate of net soot formation and oxidation in SC1A. Details of the flow field in terms of velocity vectors are shown on a vertical plane cut through the middle of the computational mesh (Figs 18 to 24). Velocity vectors are coloured, and the scale range of a colour map is shown at each CA in figures. Soot isovolumes are shown in two views of the combustion chamber at each CA: first a vertical plane cut through the middle of the computational mesh referred to as 'side view'; second is a horizontal plane cut near the cylinder head referred to as 'top view' in the present paper (Figs 22 to 25 and Figs 26 to 29). To understand soot formation, soot isovolumes are colour-mapped with $\mathrm{C}_{2} \mathrm{H}_{2}$. Similarly, $\mathrm{OH}$ radicals are colour-mapped on soot isovolumes to explain soot oxidation. The lowest and highest concentrations of $\mathrm{C}_{2} \mathrm{H}_{2}$ (or $\mathrm{OH}$ radicals) are coloured in blue and red, respectively. An enlargement of the isovolume would indicate soot formation, and a shrinking of isovolume would mean soot oxidation. For ease of visualization, the cylinder head and cylinder wall are not shown and the piston wall is made transparent. Soot formation is examined at CAs of $12^{\circ}$ and $14^{\circ}$ ATDC, whereas CAs of $28^{\circ}$ and $30^{\circ}$ ATDC are considered to study soot oxidation. First, soot formation for both rate shapes ( $\mathrm{SClA}$ and $\mathrm{SClH}$ ) is discussed, followed by their soot oxidation.

The soot formation rate for the SC1A rate shape is at its maximum around $13^{\circ}$ ATDC. The colour map scale, for velocity vectors at $12^{\circ}$ and $14^{\circ}$ ATDC, ranges from $20 \mathrm{~m} / \mathrm{s}$ (blue) to $220 \mathrm{~m} / \mathrm{s}$ (red). For both rate shapes, spray motion along the piston bowl and towards the squish region is evident from instantaneous velocity vectors at both CAs, as shown in Figs 18 and 19. However, higher magnitudes of velocity vectors in the piston bowl and squish regions at both CAs are seen for SC1A compared to $\mathrm{SClH}$. These are a result of the higher injection rate in SC1A, as shown in Fig. 5. Correspondingly, the spray-wall interaction is much stronger in SC1A with the establishment of a strong toroidal vortex inside the piston bowl. Until $11^{\circ}$ ATDC, injected fuel in $\mathrm{SClH}$ has a higher spray momentum (see Fig. 8), and thereafter spray momentum becomes dominant in SC1A due to the nature of the different rate shapes (see Fig. 5). As a result of the initial higher spray momentum in the case of $\mathrm{SC} 1 \mathrm{H}$, soot isovolumes in both views of the combustion chamber (see Fig. 24) are smaller compared to SC1A (see Fig. 22). The higher concentration of $\mathrm{C}_{2} \mathrm{H}_{2}$ along the piston bowl wall is a result of weak spray-wall interactions in $\mathrm{SC} 1 \mathrm{H}$. Due to the increased flow in the squish region (see Fig. 18(a)) in SC1A, a large amount of soot is formed and also a local higher concentration of $\mathrm{C}_{2} \mathrm{H}_{2}$ is found compared to $\mathrm{SC} 1 \mathrm{H}$. As the piston moves down (crank rotates from $12^{\circ}$ to $14^{\circ} \mathrm{ATDC}$ ), soot isovolumes in SC1A (in Fig. 23) move deeper into the piston bowl and further into the squish region. The movement of the soot isovolume deeper into the piston bowl is primarily a result of the toroidal vortex (in the 


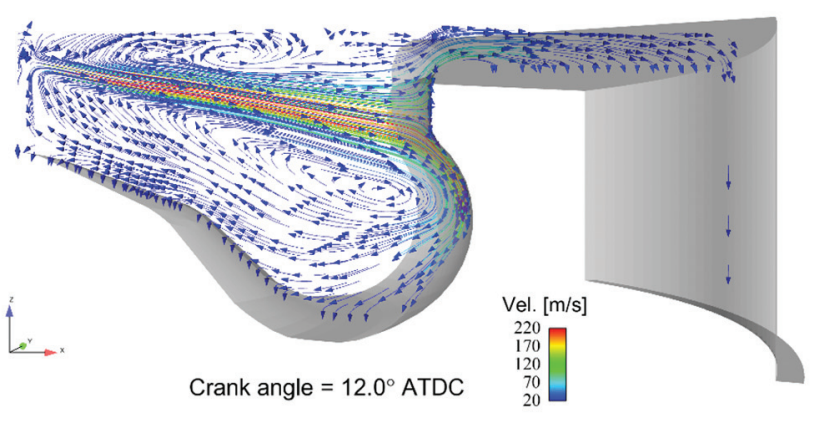

(a)

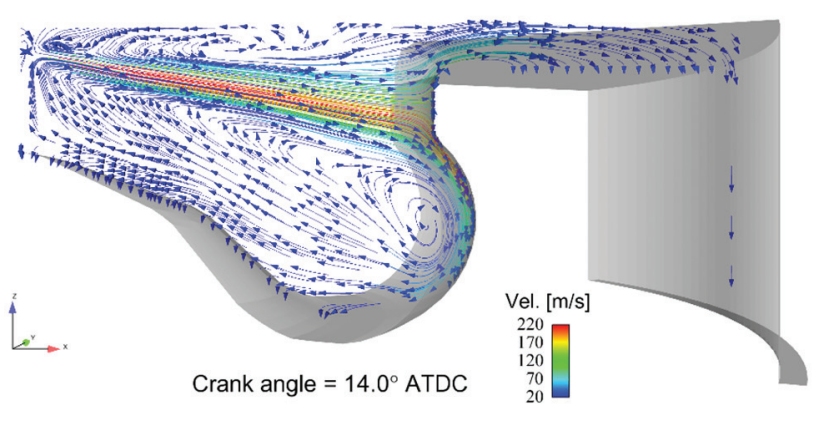

(b)

Fig. 18 Instantaneous velocity vectors on a vertical plane in SC1A (a) at $12^{\circ} \mathrm{ATDC}$, and (b) at $14^{\circ}$ ATDC

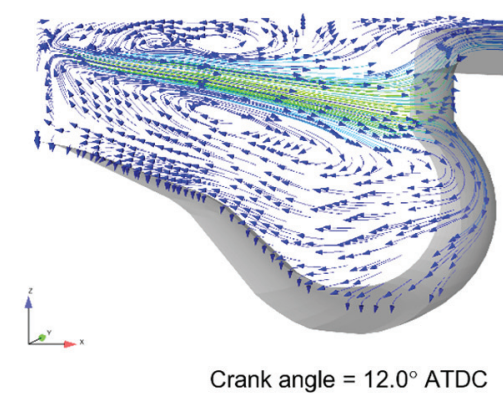

(a)

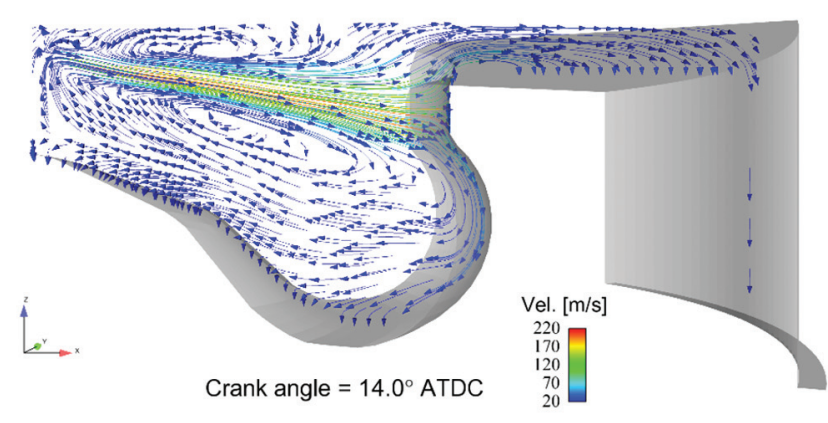

(b)

Fig. 19 Instantaneous velocity vectors on a vertical plane in $\mathrm{SC} 1 \mathrm{H}$ (a) at $12^{\circ} \mathrm{ATDC}$, and (b) at $14^{\circ}$ ATDC

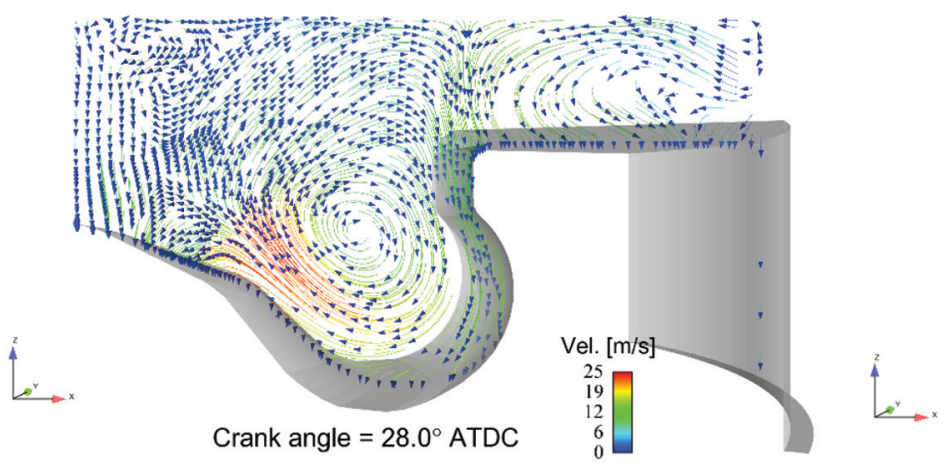

(a)

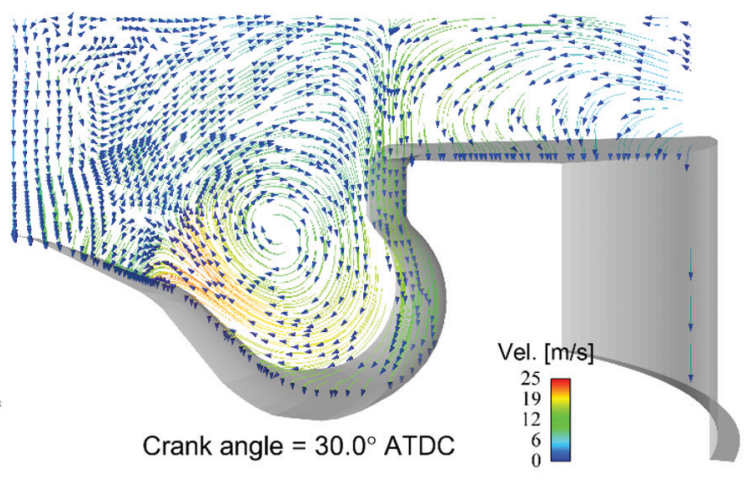

(b)

Fig. 20 Instantaneous velocity vectors on a vertical plane in SC1A (a) at $28^{\circ}$ ATDC, and (b) at $30^{\circ}$ ATDC

piston bowl region) approaching closer to the piston bowl wall and at the same time moving deeper into the piston bowl (Fig. 18(b)). Soot moving further into the squish region is due to a continued flow towards the squish region. Soot located in the squish region, as seen in the top view of Figs 22 and 23 for the SC1A rate shape, shows a growth in soot isovolumes as well as in $\mathrm{C}_{2} \mathrm{H}_{2}$ concentration. This is an indication of rich burning due to insufficient mixing. In the case of $\mathrm{SC} 1 \mathrm{H}$, the toroidal vortex is weak and has not yet come close the piston bowl wall. Thus, mixing near the wall is expected to be poor. Consequently, a thick layer of soot with a high concentration of $\mathrm{C}_{2} \mathrm{H}_{2}$ is found near the piston bowl wall, as shown in the side view in Fig. 25. Comparatively, a lower flow towards the 


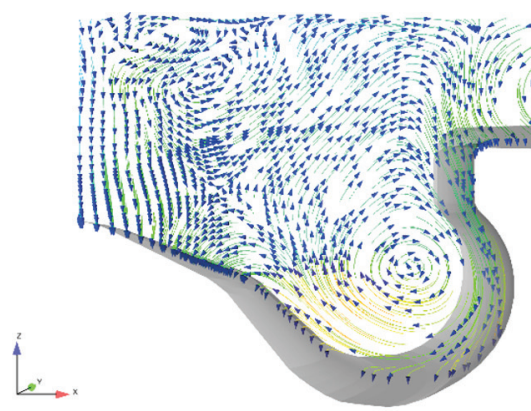

Crank angle $=28.0^{\circ}$ ATDC

(a)

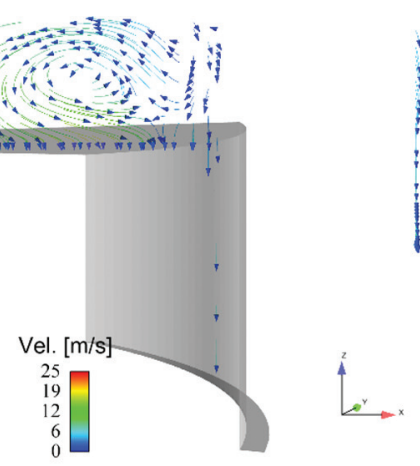

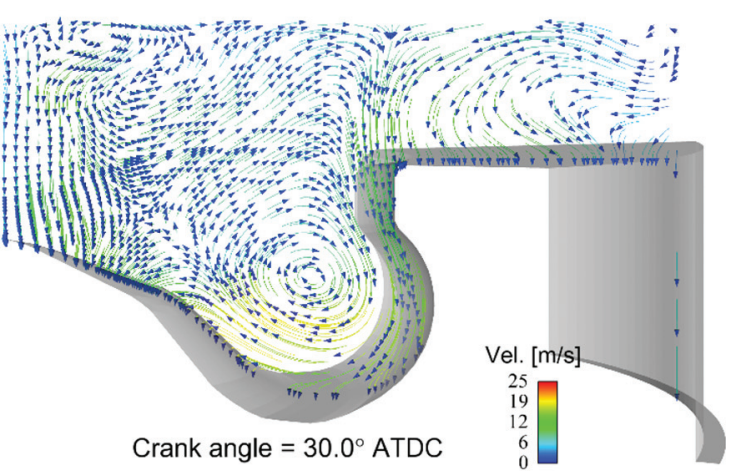

(b)

Fig. 21 Instantaneous velocity vectors on a vertical plane in SC1H (a) at $28^{\circ}$ ATDC, and (b) at $30^{\circ}$ ATDC
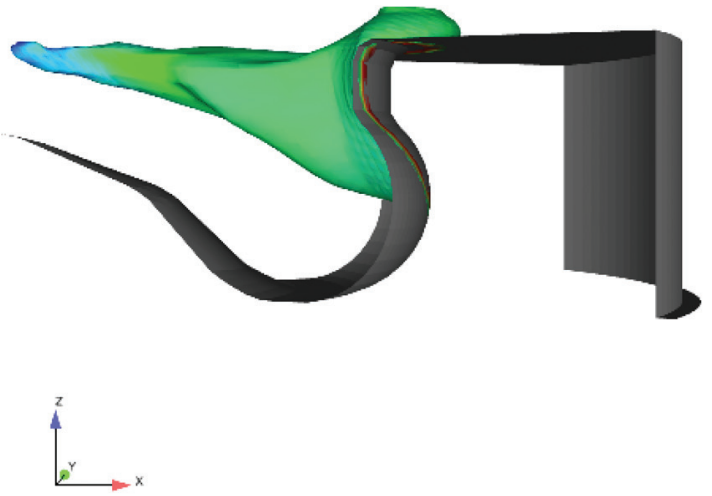
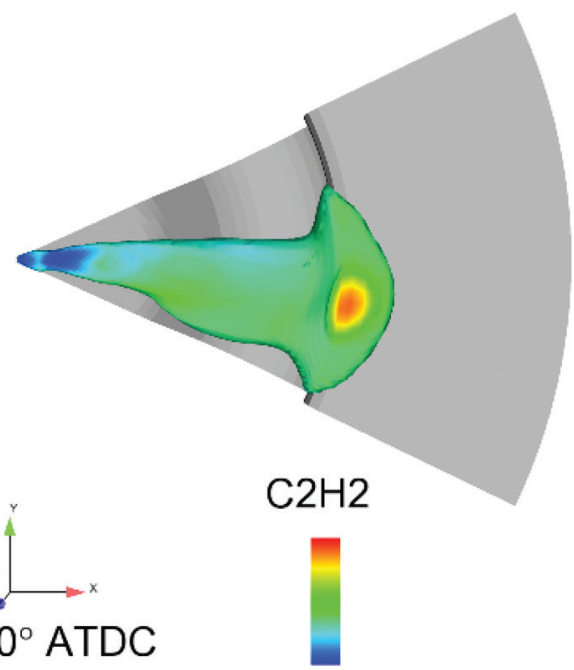

Fig. 22 Soot isovolumes coloured with $\mathrm{C}_{2} \mathrm{H}_{2}$ in SC1A at $12^{\circ}$ ATDC; lowest and highest concentration of $\mathrm{C}_{2} \mathrm{H}_{2}$ are represented in blue and red colours, respectively
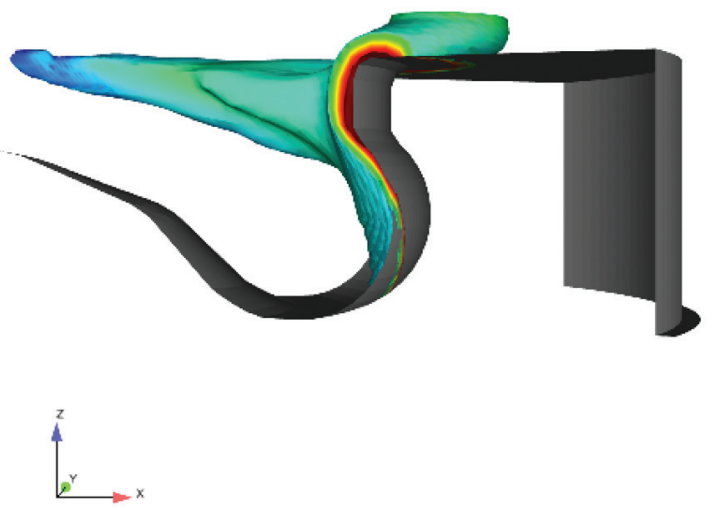
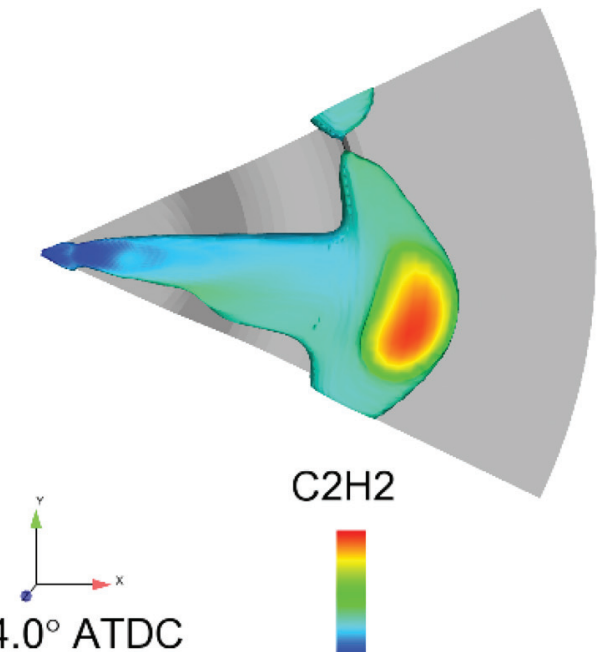

Fig. 23 Soot isovolumes coloured with $\mathrm{C}_{2} \mathrm{H}_{2}$ in SC1A at $14^{\circ}$ ATDC; lowest and highest concentration of $\mathrm{C}_{2} \mathrm{H}_{2}$ are represented in blue and red colours, respectively 

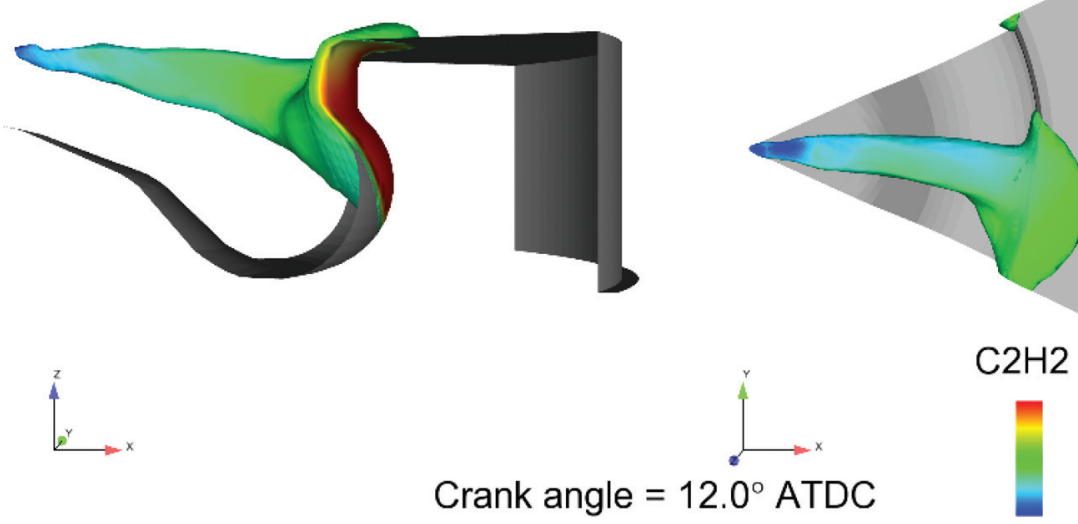

Fig. 24 Soot isovolumes coloured with $\mathrm{C}_{2} \mathrm{H}_{2}$ in $\mathrm{SC} 1 \mathrm{H}$ at $12^{\circ}$ ATDC; lowest and highest

$\underset{2^{2}}{\longrightarrow} x$

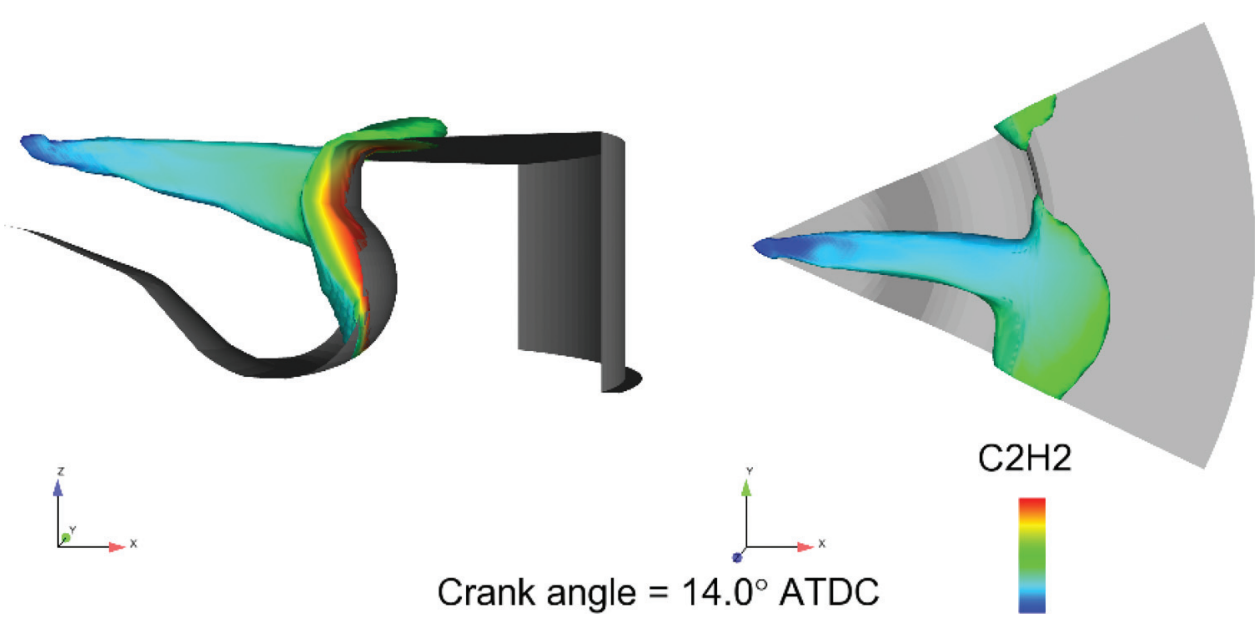

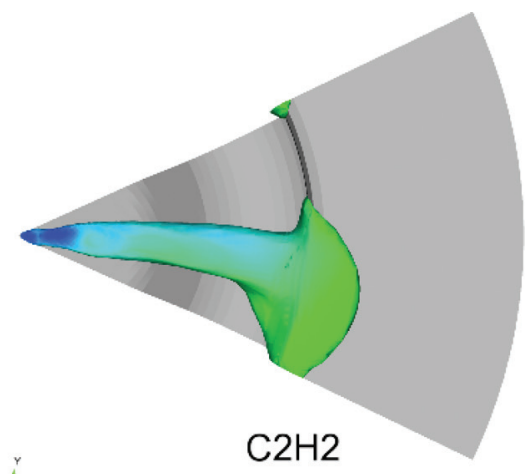

\section{concentration of $\mathrm{C}_{2} \mathrm{H}_{2}$ are represented in blue and red colours, respectively}

Fig. 25 Soot isovolumes coloured with $\mathrm{C}_{2} \mathrm{H}_{2}$ in $\mathrm{SClH}$ at $14^{\circ}$ ATDC; lowest and highest concentration of $\mathrm{C}_{2} \mathrm{H}_{2}$ are represented in blue and red colours, respectively

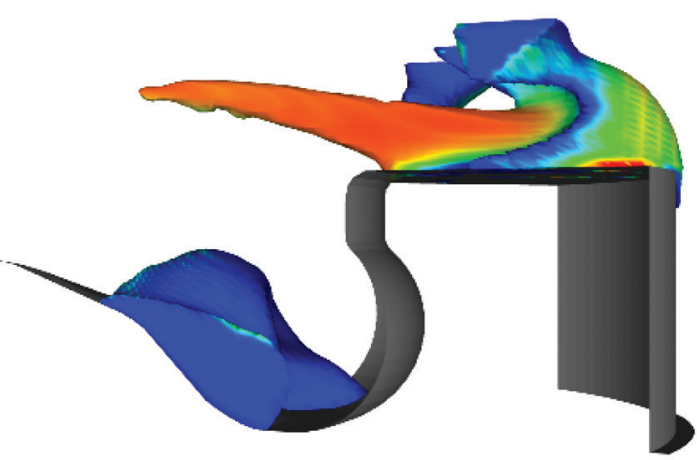

$\stackrel{2}{2}_{2}^{2} x$
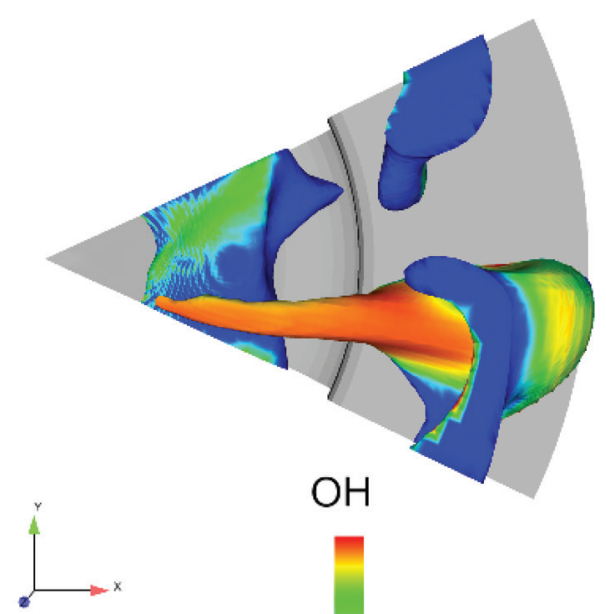

$\mathrm{OH}$

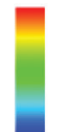

Fig. 26 Soot isovolumes coloured with $\mathrm{OH}$ in SC1A at $28^{\circ}$ ATDC; lowest and highest concentration of $\mathrm{OH}$ are represented in blue and red colours, respectively 

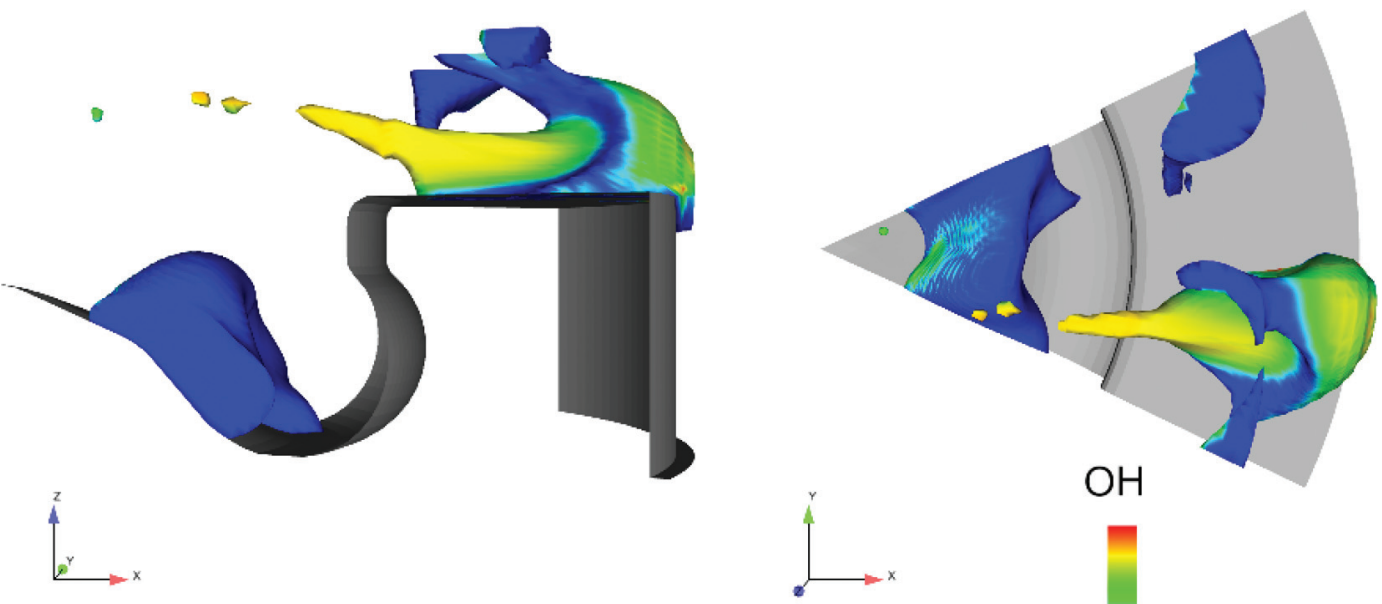

$\mathrm{OH}$

Crank angle $=30.0^{\circ}$ ATDC

Fig. 27 Soot isovolumes coloured with $\mathrm{OH}$ in SC1A at $30^{\circ}$ ATDC; lowest and highest concentration of $\mathrm{OH}$ are represented in blue and red colours, respectively

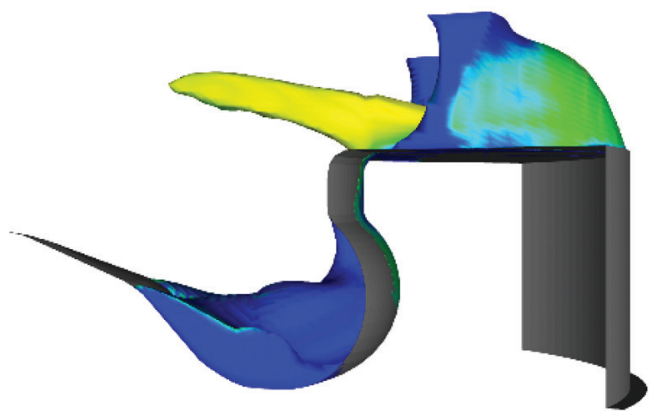

$\underset{2^{2}}{\longrightarrow} x$
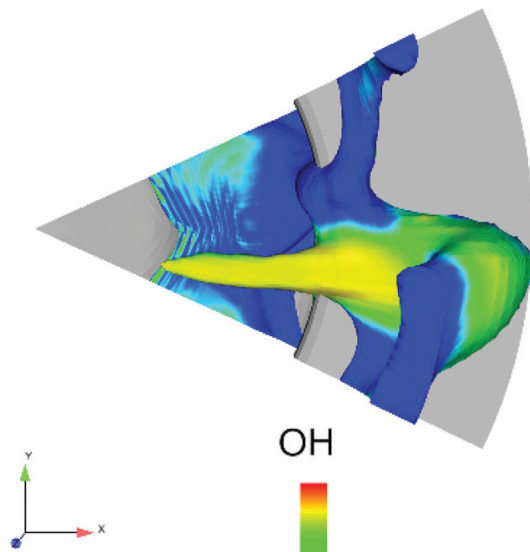

Crank angle $=28.0^{\circ}$ ATDC
$\mathrm{OH}$

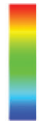

Fig. 28 Soot isovolumes coloured with $\mathrm{OH}$ in $\mathrm{SC} 1 \mathrm{H}$ at $28^{\circ}$ ATDC; lowest and highest concentration of $\mathrm{OH}$ are represented in blue and red colours, respectively

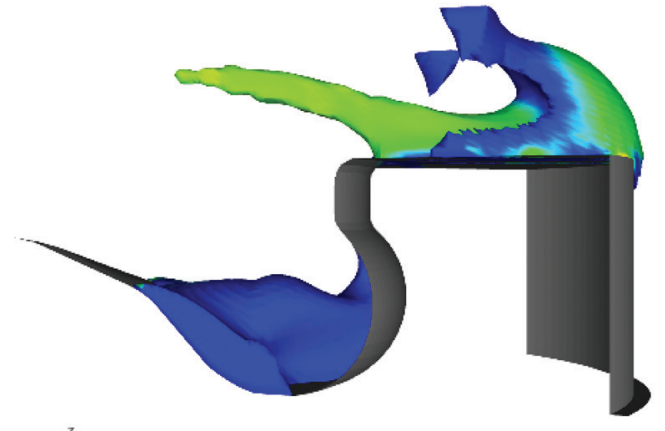

$\underset{2^{2}}{2} x$
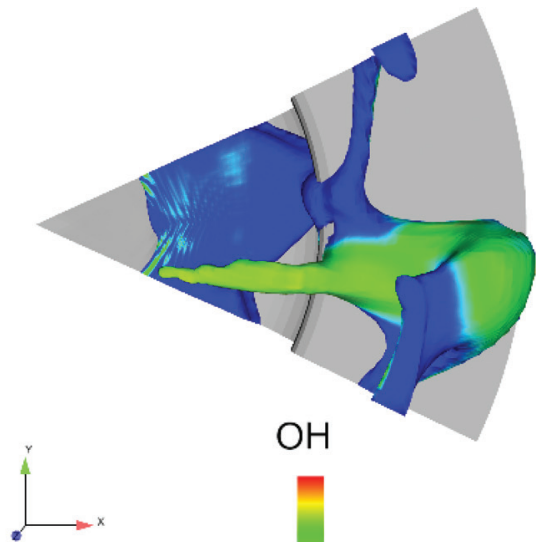

Crank angle $=30.0^{\circ}$ ATDC

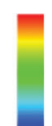

Fig. 29 Soot isovolumes coloured with $\mathrm{OH}$ in $\mathrm{SC} 1 \mathrm{H}$ at $30^{\circ}$ ATDC; lowest and highest concentration of $\mathrm{OH}$ are represented in blue and red colours, respectively 
squish region in $\mathrm{SC1H}$ causes lower growth of soot isovolumes in squish.

The top view of the combustion chamber in both rate shapes shows two separated soot isovolumes inside the squish region near the top and bottom walls of Figs. 23 and 25. This indicates the presence of swirl motion in a clockwise direction for both rate shapes.

At near $29^{\circ}$ ATDC, the soot oxidation rate is at its maximum in SC1A (see Fig. 17). Figures 20, 21, and 26 to 29 show the flow field and soot isovolumes at $28^{\circ}$ and $30^{\circ}$ ATDC for both rate shapes. For velocity vectors, the colour map scale ranges from zero (blue) to $25 \mathrm{~m} / \mathrm{s}$ (red). At the end of injection $\left(19.8^{\circ}\right.$ ATDC), SC1A ends up with a significantly higher injected spray momentum, starting from around $11^{\circ}$ ATDC, compared to $\mathrm{SC} 1 \mathrm{H}$ due to the nature of the different rate shapes (see Fig. 8). Thus, the last 30 per cent of the total injected fuel amount has entered the cylinder with a much higher cumulative momentum in SC1A (see Figs. 7 and 8). Accordingly, a comparison at $28^{\circ}$ ATDC (in Figs 20(a) and 21(a)) shows that SC1A has a wider toroidal vortex inside the piston bowl region compared to $\mathrm{SClH}$. The toroidal vortex in SClA, when compared with $\mathrm{SC} 1 \mathrm{H}$ at $14^{\circ}$ ATDC, has moved towards the centre of the bowl, whereas in $\mathrm{SC} 1 \mathrm{H}$, for the same piston displacement, the vortex is somewhat close to the piston bowl wall. As the crank rotates from $28^{\circ}$ to $30^{\circ}$ ATDC (piston travels down), the toroidal vortex inside the bowl region moves towards the cylinder axis for both rate shapes. As a result, the soot isovolume inside the bowl region moves further towards the cylinder axis. During that period, the strong vortex motion in SC1A results in a higher displacement of the soot isovolume inside the piston bowl. The lower spray momentum at the end of the fuel injection in $\mathrm{SC} 1 \mathrm{H}$ translates into a lower displacement of the soot isovolume inside the piston bowl region due to a weak toroidal vortex. Higher concentrations of $\mathrm{OH}$ radicals seen on the soot isovolume (connected to the squish region), shown in both views of the combustion chamber in Fig. 26, are due to a wider toroidal vortex in SC1A. From a comparison at $30^{\circ}$ ATDC it can be concluded that the higher the $\mathrm{OH}$ concentration, the higher is the soot oxidation level. Due to a lower concentration of $\mathrm{OH}$ radicals in $\mathrm{SC} 1 \mathrm{H}$, soot oxidation is lower in the combustion chamber compared to SC1A.

An examination of soot formation and oxidation for both rate shapes has revealed their differences. In $\mathrm{SC} 1 \mathrm{H}$, considering the initial higher spray momentum, soot formation rates are lower, but the lower total spray momentum at the end of the fuel injection causes poor oxidation of soot, i.e. lower oxidation rates. In SC1A, formation (and formation rate) is higher due to the initial lower momentum and increased flow towards the squish region. However, the efficient oxidation at later CAs results in the lowest soot (and higher rates of oxidation) at EVO.

\subsection{Boot injection rate: variation-2 (SC2)}

The numerical investigation in variation-1 showed significant dependence of the engine performance (at a single engine load point) on investigated injection-rate shapes. In particular, the injectionrate shapes SC1A to SC1D offer significant potential for diesel engine application. The SC1A injectionrate shape, the one with the lowest injected fuel mass in the first stage of the boot injection shape (see Fig. 5), is chosen as the baseline case for variation-2. In this section, SC1A is referred to as SC2B. The investigated boot injection-rate shapes in variation-2 are shown in Fig. 30. The effects of six different rate shapes, SC2A to SC2F, on the engine performance are analysed. In variation-2, the height of the second stage of the boot injection shape is varied with a constant boot height of the first stage being taken (Fig. 30). Injected fuel mass in the first stage of the boot injection shape is shown in Fig. 31. Compared to variation-1 (Fig. 6), the injected fuel mass in the first stage only varies within the range from 9 to 13 per cent. The variation of mass in the first stage is expected to affect the engine performance only minimally, as noticed in the comparison of case SC1A with SC1B (injected fuel mass varied in the first stage between 10 and 16 per cent). Injection-rate shapes SC2B and SC1A (see Fig. 5) are identical. Therefore, the results of SC1A instead of SC2B are taken for comparison in this section. In Figs 32 and 33, the normalized cumulative mass of the injected fuel and the cumulative spray momentum over the duration of the fuel injection are shown for the SC2B and SC2F rate shapes. The total spray momentum at the end of the fuel injection is highest in SC2F. Until $5^{\circ}$ ATDC, the injected fuel in both rate shapes has the same spray momentum. Compared to SC2F, around 62 per cent of the total injected fuel mass has a higher cumulative spray momentum in SC2B. The last 38 per cent of the total fuel mass in SC2F is injected with a significantly higher cumulative spray momentum.

\subsubsection{Global results}

It was shown in the previous section that the trends in fuel evaporation correspond to their injection profile. Since in this section the considered engine 


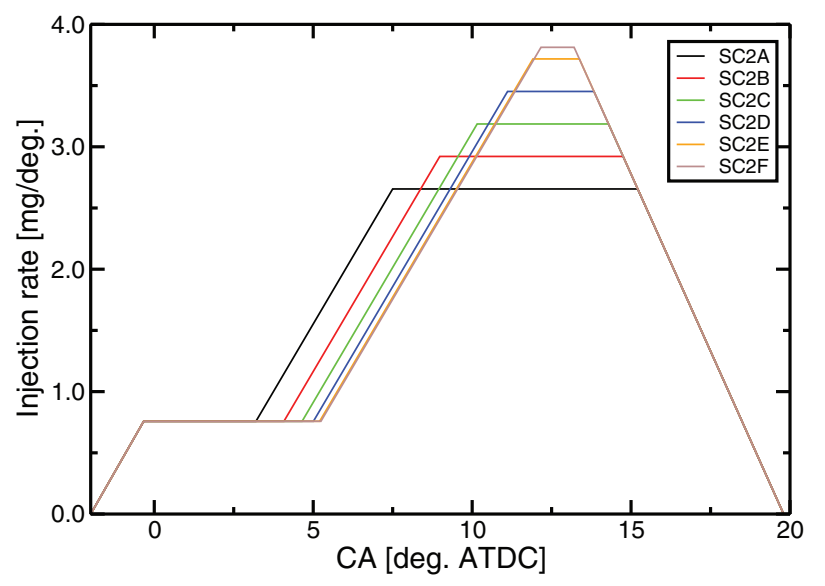

Fig. 30 Fuel injection-rate profile for different rate shapes in variation-2

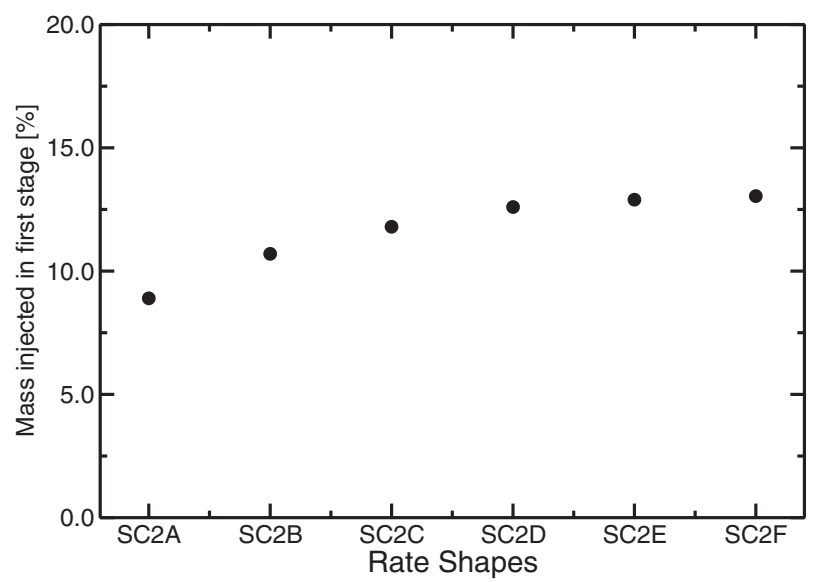

Fig. 31 Injected fuel mass in the first stage of the boot shape in variation-2, shown as a percentage of the overall total injected fuel mass

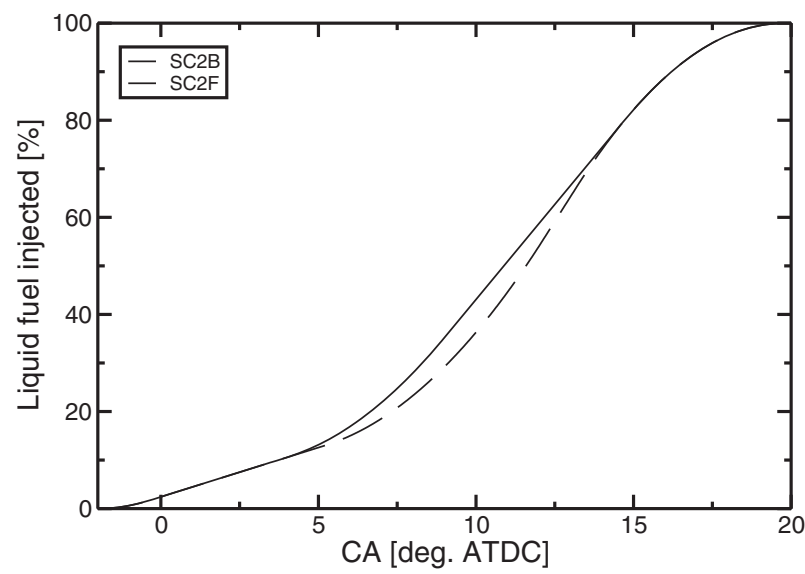

Fig. 32 Comparison of the normalized cumulative injected fuel mass for the SC2B and SC2F rate shapes in variation-2

operating conditions are the same as in the last section, the conclusions for evaporation rates are not expected to change. Therefore, evaporation rates

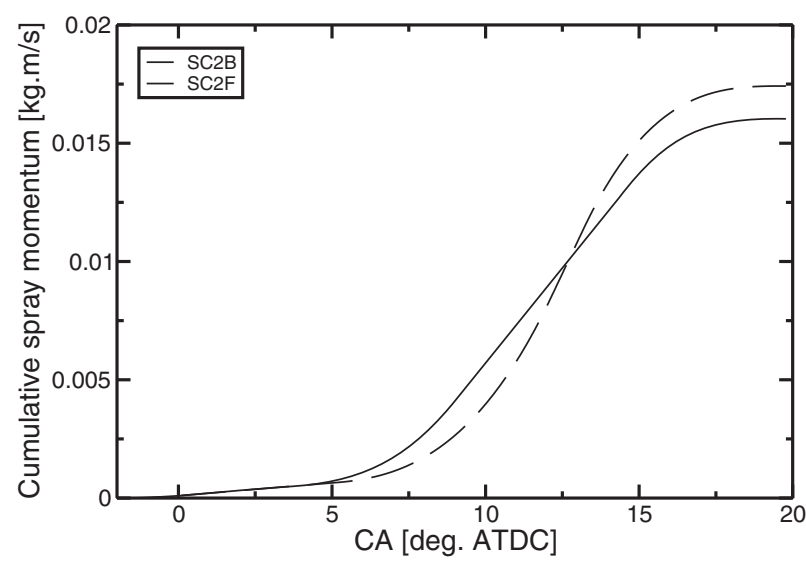

Fig. 33 Comparison of the cumulative spray momentum for the SC2B and SC2F rate shapes

are not discussed in this section. Figure 34 shows the computed in-cylinder averaged pressure histories for the different injection-rate shapes in variation-2. The start of the fuel injection is at $-2^{\circ}$ ATDC and the end of the fuel injection is at $19.8^{\circ}$ ATDC, as also shown in Fig. 34 (blue line). With increasing boot height in the second stage, the phasing of the cylinder peak pressure retards and the cylinder peak pressure decreases. The lower fuel injection rate at the first stage of the boot shape implies a higher injection rate in the second stage of the boot shape in order to maintain a constant total injection duration and total injected fuel mass (see Fig. 30). Higher injection rates in the second stage, when the piston is travelling down during the expansion stroke, cause a lower cylinder peak pressure, and its phasing is also retarded. One can state that the rate shapes in variation-2 can further decrease the peak pressure in the cylinder.

Variations of the heat release rate as a function of CA are shown for SC2A, SC2C, and SC2E in Fig. 35. The higher value of the premixed spike in SC2A, compared to the other two rate shapes, can be attributed to the shorter duration of the injection in the first stage and the relatively higher fuel injection rate until $7^{\circ}$ ATDC (see Fig. 30), resulting in higher evaporation rates. The longer injection duration of the first stage, in SC2C and SC2E compared to SC2A (Fig. 30), has only an insignificant affect on the value of the premixed spike (similar evaporation rates are expected). The heat release rate during the diffusion phase of burning (following the premixed spike) shows a dependence on the injection profile in the second stage of the boot shape (see Fig. 35). The higher fuel injection rate enhances fuel-air mixing, thereby increasing the heat release rate during the diffusion phase of burning.

The ringing intensity for all rate shapes in variation-2 is below the highest acceptable limit of 


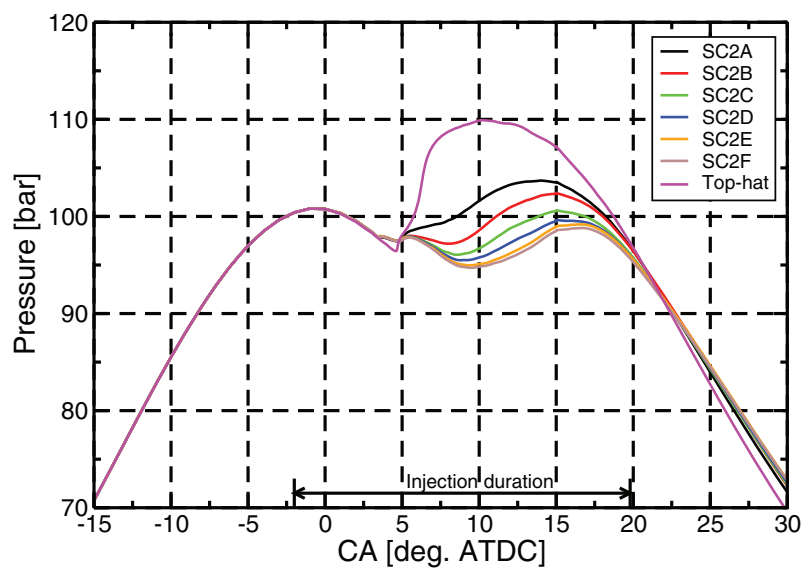

Fig. 34 Simulated cylinder pressure histories of the different rate shapes in variation-2

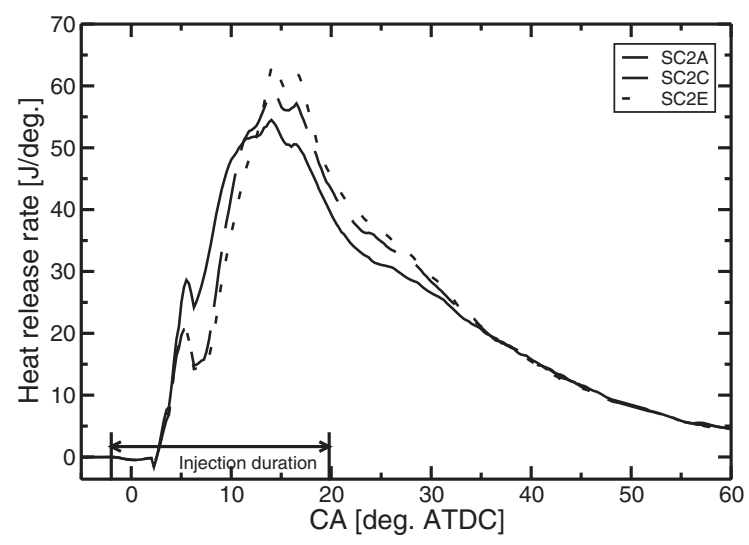

Fig. 35 Calculated heat release rates for SC2A, SC2C, and SC2E rate shapes in variation-2

3.0 $\mathrm{MW} / \mathrm{m}^{2}$, and varies only slightly for different rate shapes, as shown in Fig. 36. As mentioned in the last section, combustion-generated noise is controlled by the early part of the combustion process; that is the initial rapid heat release immediately following the ignition-delay. Due to a smaller change in the initial heat release rate for different rate shapes, as seen in Fig. 35, one can state that the injection-rate shapes in variation-2 (Fig. 30) have little affect on combustion-generated noise.

Net in-cylinder soot (expressed in grams per kilogram of fuel) is shown in Fig. 37 for all rate shapes in variation-2. Compared to SC2B, the reduction in net in-cylinder soot is noticeable when the boot height in the second stage is increased (rate shapes SC2C to SC2F). An increase in net in-cylinder soot level is possible when the boot height in the second stage is decreased (SC2A rate shape). This trend can clearly be related to the degree of mixing and the boot height of the second stage.

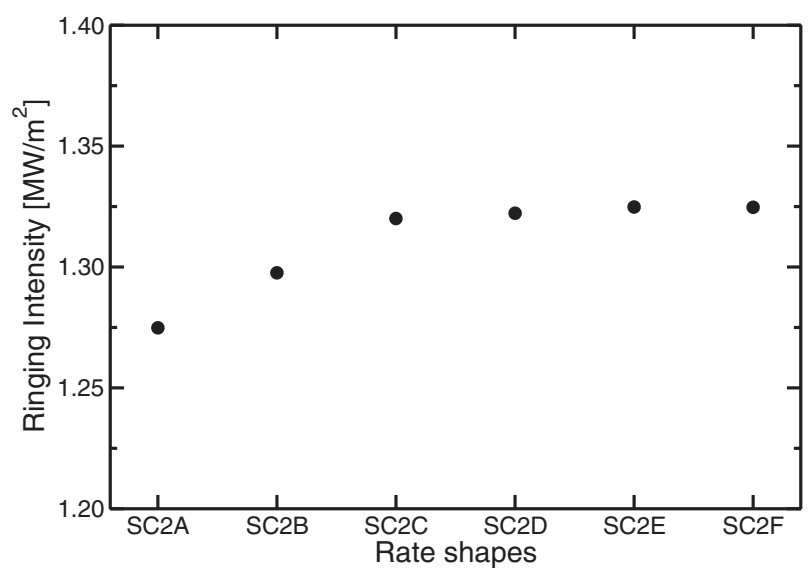

Fig. 36 Comparison of the ringing intensity (or combustion-generated noise) for different rate shapes in variation-2

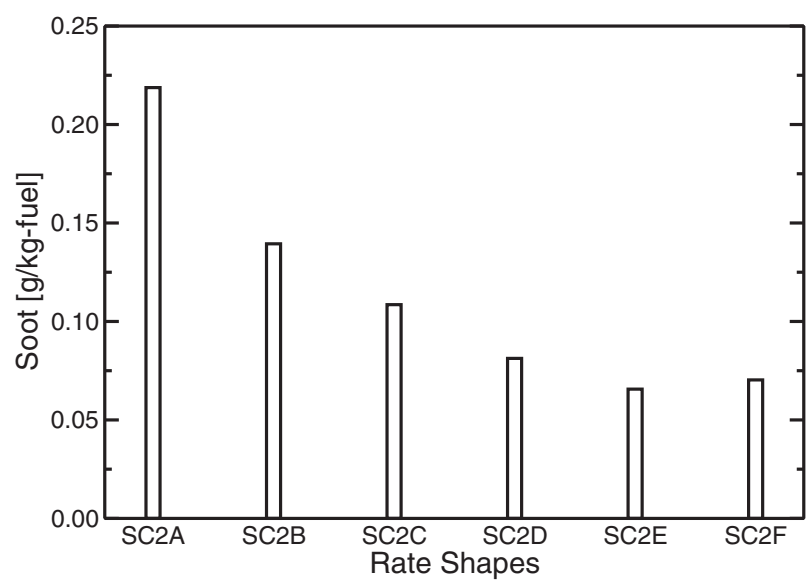

Fig. 37 Soot emissions at EVO for different rate shapes in variation-2

Total in-cylinder $\mathrm{NO}_{x}$ (expressed in grams per kilogram of fuel) at EVO are shown in Fig. 38 for different injection-rate shapes. The boot height variation in the second stage shows minor differences in $\mathrm{NO}_{x}$ emissions. It can be concluded that by increasing the boot height of the second stage, the net incylinder soot level at EVO can be reduced without increasing $\mathrm{NO}_{x}$ emissions at EVO, i.e. avoiding the typical soot- $\mathrm{NO}_{x}$ trade-off.

\subsubsection{Detailed analysis of soot formation and oxidation}

The temporal distribution of the net in-cylinder soot level in Fig. 39 indicates that a large fraction of the soot formed is oxidized within the cylinder before the exhaust process commences. The increase of the boot height of the second stage, on the one hand, enhances soot formation, and on the other hand, also increases soot oxidation. 


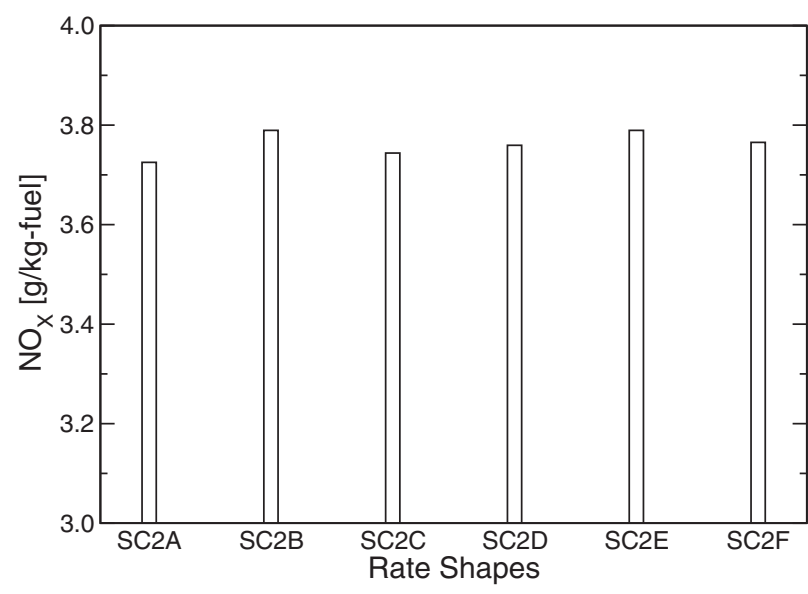

Fig. $38 \mathrm{NO}_{x}$ emissions at EVO for different rate shapes in variation-2

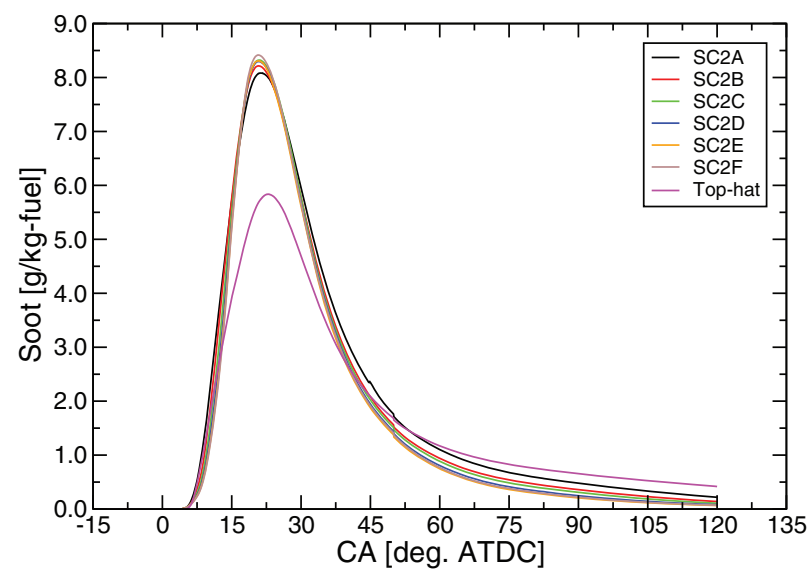

Fig. 39 Net in-cylinder soot level as a function of CA for different rate shapes in variation-2

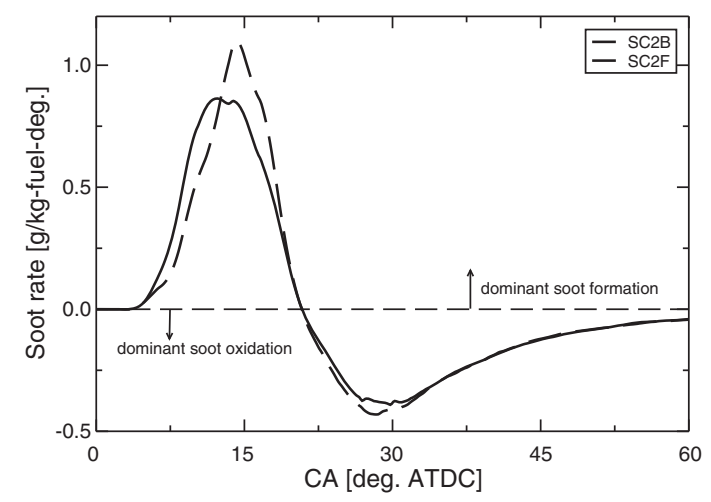

Fig. 40 Net soot rate (time derivative of net incylinder soot) for SC2B and SC2F rate shapes in variation-2

Therefore, soot emissions at EVO decrease with increasing boot height of the second stage, as also seen in Fig. 37. Figure 40 compares the net soot rate in SC2B and SC2F. Higher soot formation rates in
SC2F result in the highest peak in soot formation among all rate shapes (see Fig. 37). However, compared with SC2B, the soot oxidation rates are also high for this rate shape, resulting in a lower net incylinder soot level at EVO.

As in the previous section, soot formation and oxidation are studied at the same CAs for the SC2F rate shape. In order to explain the trends of net soot level at EVO, the results of SC2F are compared with the SC2B (or the SC1A) rate shape. The flow field (in terms of instantaneous velocity vectors) and soot isovolumes coloured with $\mathrm{C}_{2} \mathrm{H}_{2}$ are examined for soot formation. Soot oxidation is understood with the help of the flow field and soot isovolumes coloured with $\mathrm{OH}$ radicals. Soot isovolumes, as in the previous section, are shown in top and side views of the combustion chamber. The concentration scale of $\mathrm{C}_{2} \mathrm{H}_{2}$ (or $\mathrm{OH}$ radicals) ranges between low (blue) and high (red). The flow field is shown on a vertical plane cut through the middle of the computational mesh. Instantaneous velocity vectors are coloured to represent their magnitude, and the scale range of a colour map is also shown at each CA.

Soot formation is examined at $12^{\circ}$ and $14^{\circ}$ ATDC. Figure 41 shows instantaneous velocity vectors at both CAs in SC2F. Corresponding soot isovolumes are shown in Figs 42 and 43 in both views of the combustion chamber. The colour map scale for velocity vectors ranges from $20 \mathrm{~m} / \mathrm{s}$ (blue) to $220 \mathrm{~m} / \mathrm{s}$ (red) at both CAs. At $12^{\circ}$ ATDC, SC2F has a lower injected fuel mass and spray momentum compared with SC2B (see Figs 32 and 33). Additionally, the initial evaporation rate in SC2F is expected to be lower due to the initial lower fuel injection rate, as concluded in the previous section for rate shapes (Figs 5 and 9). Therefore, the lower amount of soot compared with SC2B, in both views of the combustion chamber at $12^{\circ}$ ATDC is the result of the lower injected fuel mass and its evaporation (see soot isovolumes in Figs 22, 23, 42, and 43). After $12.5^{\circ}$ ATDC, the spray momentum dominates in SC2F which ends up with a significantly higher spray momentum, as shown in Fig. 33. Therefore, the injected fuel mass after $12.5^{\circ}$ ATDC in SC2F is expected to be better mixed. As the piston travels down to the corresponding $14^{\circ}$ ATDC CA the injection rate achieves its maximum in SC2F, which is significantly higher than in SC2B. As a result of the higher injection rate, vortices in the combustion chamber, during the same period, are pushed faster towards the piston bowl wall and the squish region (compare Fig. 41(a) and Fig. 41(b) with Fig. 18). This intensifies mixing near the piston bowl wall and pushes more flow towards the squish 


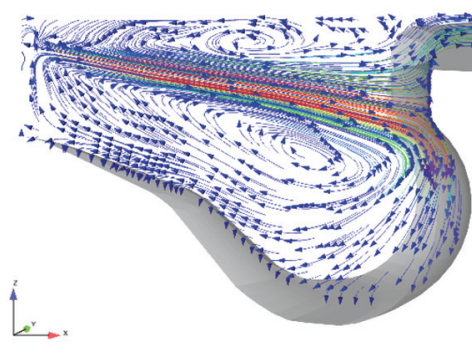

Crank angle $=12.0^{\circ}$ ATDC

(a)

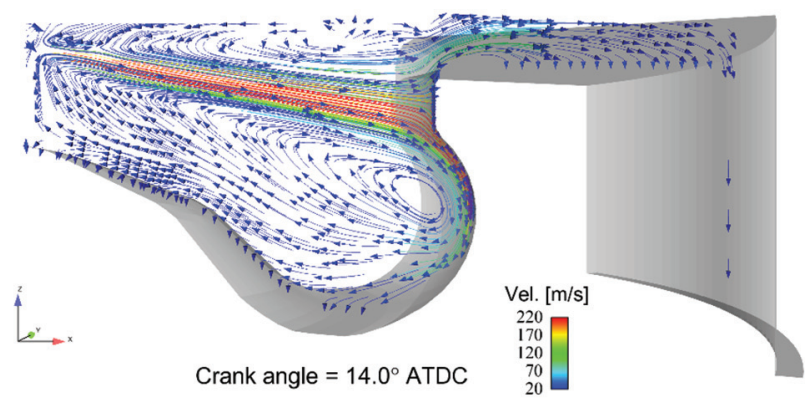

(b)

Fig. 41 Instantaneous velocity vectors on a vertical plane in SC2F (a) at $12^{\circ}$ ATDC, and (b) at $14^{\circ}$ ATDC
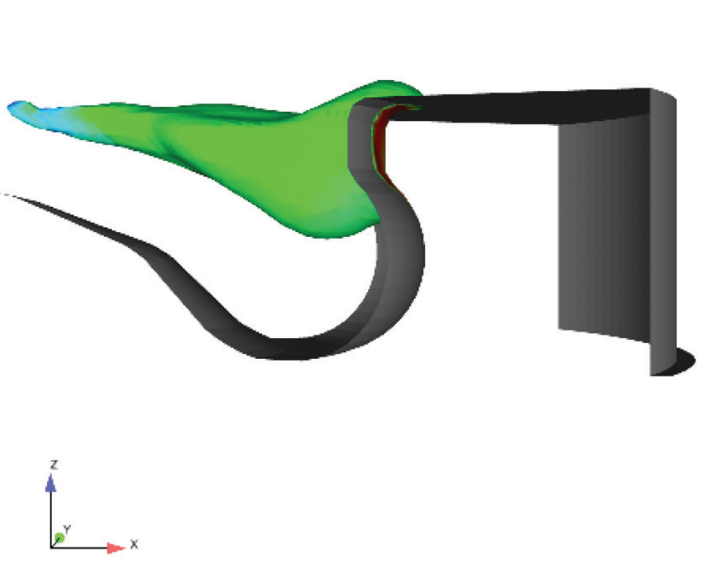

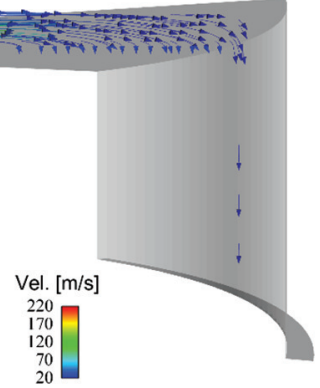

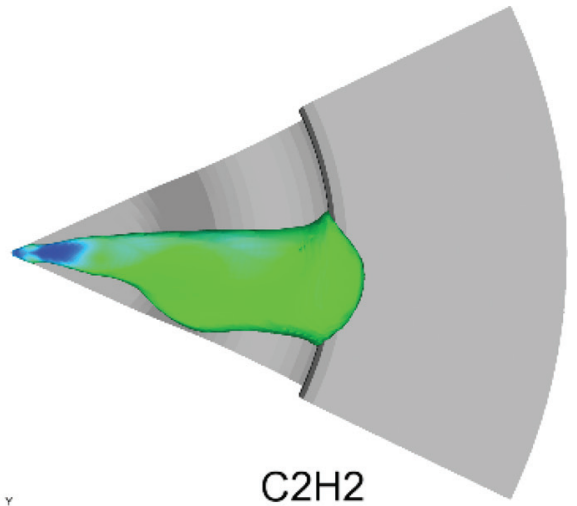
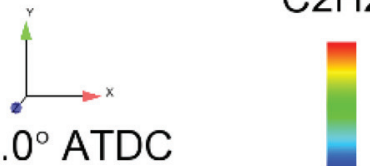

Fig. 42 Soot isovolumes coloured with $\mathrm{C}_{2} \mathrm{H}_{2}$ in SC2F at $12^{\circ}$ ATDC; lowest and highest concentration of $\mathrm{C}_{2} \mathrm{H}_{2}$ are represented in blue and red colours, respectively
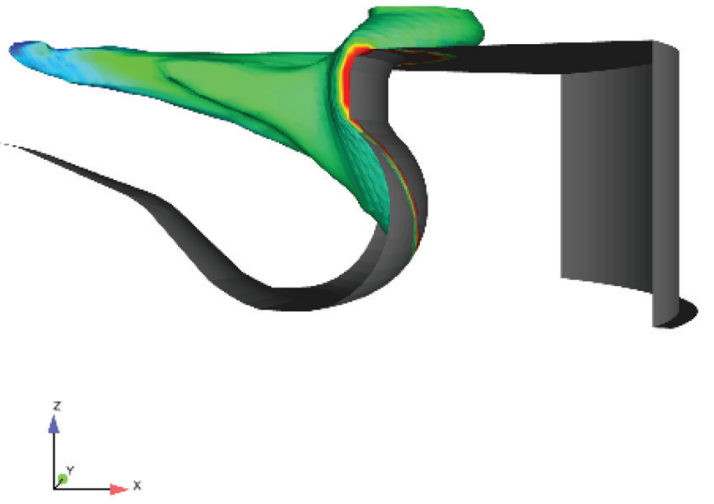
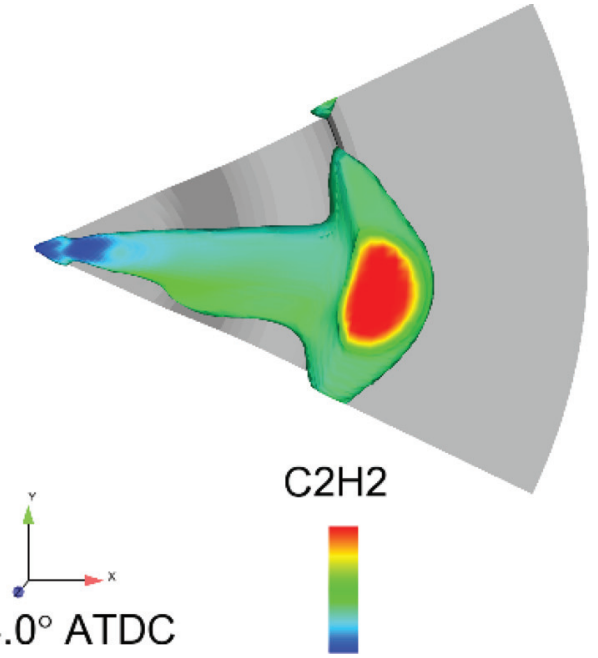

Fig. 43 Soot isovolumes coloured with $\mathrm{C}_{2} \mathrm{H}_{2}$ in SC2F at $14^{\circ}$ ATDC; lowest and highest concentration of $\mathrm{C}_{2} \mathrm{H}_{2}$ are represented in blue and red colours, respectively

region in SC2F. Consequently, soot formation, for the same period, is higher in the squish region in $\mathrm{SC} 2 \mathrm{~F}$ compared to SC2B. Increased flow towards the squish region at $14^{\circ}$ ATDC results in higher soot formation in SC2F. Similar to the vortex near the piston bowl wall, soot is also seen near the wall in 
Fig.43. Overall, higher concentrations of $\mathrm{C}_{2} \mathrm{H}_{2}$ are seen in both views of the combustion chamber in SC2F (Figs 23 and 43). This indicates the higher soot formation rates in SC2F at adjacent CAs, as also shown in Fig. 40.

Similar to the previous section, soot oxidation in this section is investigated at $28^{\circ}$ and $30^{\circ}$ ATDC. Figures 44 to 46 show the flow field and soot isovolumes at both CAs in the combustion chamber for the SC2F rate shape. For the velocity vectors, the colour map scale ranges from zero (blue) to $25 \mathrm{~m} / \mathrm{s}$ (red). At the end of the fuel injection, the SC2F rate shape ends up with a higher spray momentum compared to SC2B (see Fig. 33). The last 28 per cent of the total fuel mass enters with a higher momentum in SC2F. Correspondingly, mixing in SC2F will be superior to mixing in SC2B. As a result of higher mixing, the soot isovolumes located inside the piston bowl and squish regions are smaller than in SC2B at $28^{\circ}$ ATDC (Fig. 45). Due to minor differences in the flow field on a vertical plane (Figs 20 and 44) at both CAs, the soot isovolume location inside the piston bowl region is roughly the same for both rate shapes. As the CA advances from $28^{\circ}$ to $30^{\circ}$ ATDC, soot oxidation in both regions of the combustion chamber continues for both rate shapes, as shown in Figs 29 and 46. However, a higher oxidation of soot (especially in the squish region) in SC2F is clearly noticeable. During the same period, soot located inside the piston bowl is partly oxidized and pushed towards the cylinder axis for both rate shapes (side view in Figs. 29 and 46). Higher $\mathrm{OH}$ concentrations on the soot isovolumes at $30^{\circ}$ ATDC highlight the reason of higher soot oxidation in $\mathrm{SC} 2 \mathrm{~F}$ at subsequent CAs.

For the SC2B and SC2F rate shapes, the investigation of soot formation and oxidation has clearly revealed their differences. The relatively longer duration of the first stage of the boot shape in SC2F results in higher soot formation (and the highest peak in soot formation rate) compared to SC2B. Despite higher soot formation, the higher rates of soot oxidation in SC2F, as a result of the higher fuel injection rate and spray momentum, decreased the amount of net soot at EVO.

\section{SUMMARY AND CONCLUSIONS}

A computational study was carried out in a singlecylinder small-bore diesel engine at a high-load point of the engine. Injection-rate shapes, one of the measures to control fuel-air mixing, were simulated to understand their influence on the engine performance and the temporal response of $\mathrm{NO}_{x}$ and net soot formation levels. The peak injection rate of both stages of the boot shape was varied to obtain different injection-rate shapes. The computations were performed using a RIF model. A detailed analysis of soot formation and oxidation in the cylinder was performed by analysing flow field and soot isovolumes for some selected rate shapes. The flow field was shown in terms of instantaneous velocity vectors. Soot isovolumes were coloured with $\mathrm{C}_{2} \mathrm{H}_{2}$ to observe soot formation; oxidation of soot was observed by mapping $\mathrm{OH}$ radicals on soot isovolumes. The analysis revealed the effect of temporal distribution of injected fuel (injection-rate shaping) on soot formation and oxidation. The following key conclusions can be drawn from the computational study.

1. At the investigated load point, the boot injection-rate shapes, compared to the top-hat shape, show a strong potential to simultaneously improve combustion-generated noise and decrease soot emissions at EVO.

2. As the boot height of the first stage is decreased (lower initial injected fuel mass), the initial rapid rise of the heat release slowed down, resulting in the lower combustion-generated noise compared to the top-hat shape. Incylinder soot history strongly depends on the injection-rate shape. Lowering the boot height of the first stage does not necessarily reduce soot emissions. The boot height variation does not significantly affect $\mathrm{NO}_{x}$ emissions at EVO. Injection-rate shapes, in which up to 30 per cent of the total fuel mass (injection-rate shapes from SC1A to SC1D) are injected in the first stage of the boot shape, show improvement for combustion-generated noise, as well as soot and $\mathrm{NO}_{x}$ emissions.

3. Due to a minor change in the injected fuel mass of the first stage, the initial rapid heat release changes slightly. The diffusion phase of the heat release rate can be closely correlated to the increase in the boot height of the second stage in analogous fashion. Due to the fact that combustion-generated noise is mainly controlled by the initial rapid rise of heat release, noise increases moderately with the boot height of the second stage. A reduction in soot emissions is possible by increasing the boot height of the second stage (due to enhanced mixing rates). $\mathrm{NO}_{x}$ emissions at EVO show the insignificant effect of all rate shapes in variation-2.

4. The analysis of soot formation and oxidation showed that both processes are equally important for net in-cylinder soot reduction. Lowering the boot height of the first stage has the 


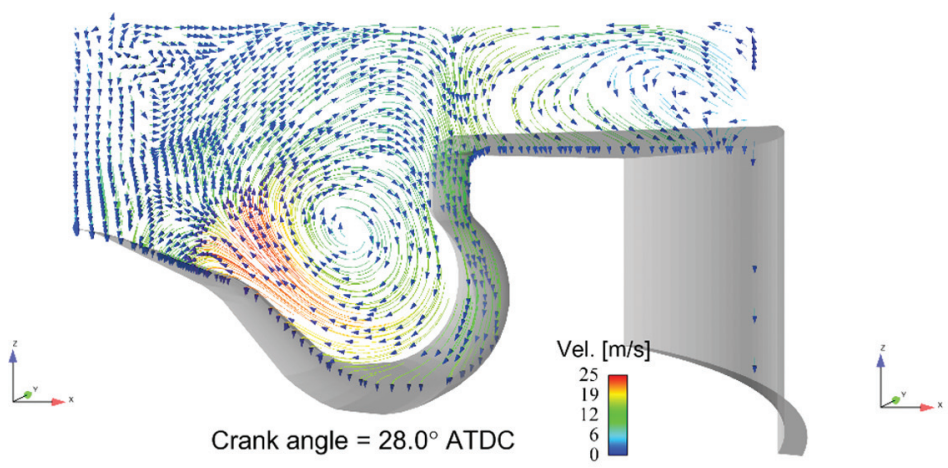

(a)

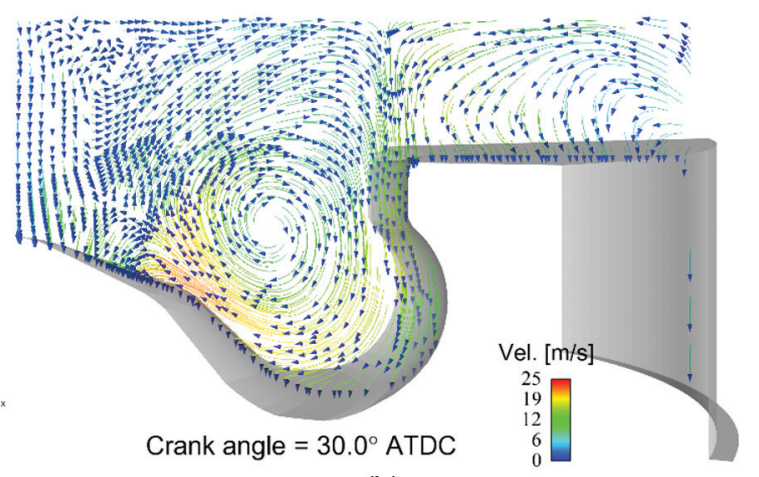

(b)

Fig. 44 Instantaneous velocity vectors on a vertical plane in SC2F (a) at $28^{\circ}$ ATDC, and (b) at $30^{\circ}$ ATDC

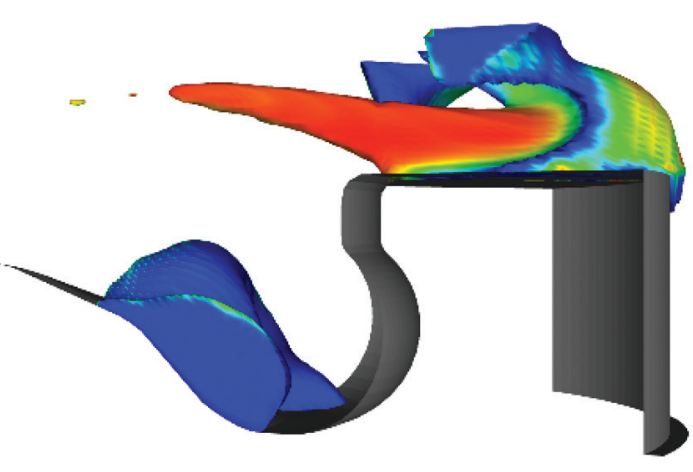

$\stackrel{2}{x}_{\longrightarrow x}^{2}$
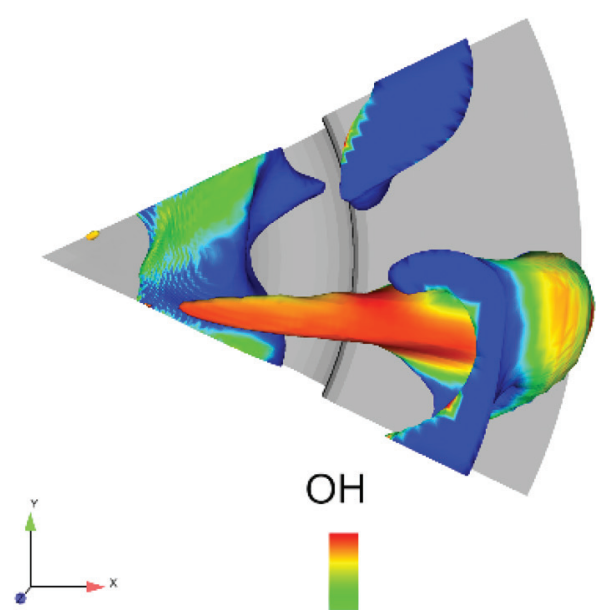

$\mathrm{OH}$

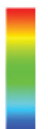

Fig. 45 Soot isovolumes coloured with $\mathrm{OH}$ in SC2F at $28^{\circ}$ ATDC; lowest and highest concentration of $\mathrm{OH}$ are represented in blue and red colours, respectively

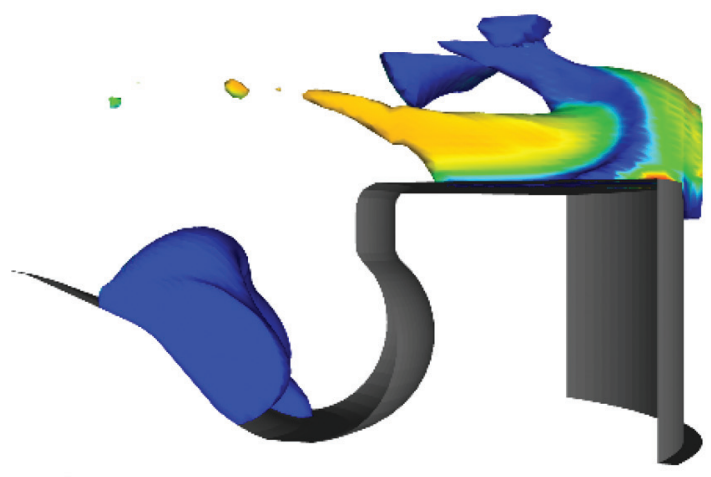

$\underset{t^{y}}{\stackrel{2}{\longrightarrow} x}$
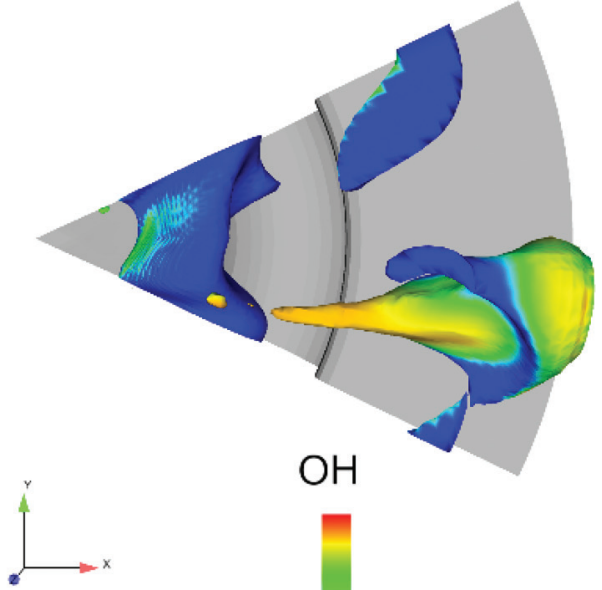

$\mathrm{OH}$

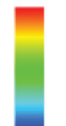

Fig. 46 Soot isovolumes coloured with $\mathrm{OH}$ in SC2F at $30^{\circ}$ ATDC; lowest and highest concentration of $\mathrm{OH}$ are represented in blue and red colours, respectively 
tendency to increase soot formation due to a lower injection rate and spray momentum. The enhancement in soot oxidation with increasing boot height of the second stage is due to the higher injection rate and spray momentum. Therefore, depending on the boot rate shape, the net soot level at EVO could be increased or decreased.

5. Based on these conclusions, one can state that temporal distribution of fuel for a given injection duration (and depending on the engine operating point) could be a dynamic control parameter in diesel engine combustion.

\section{ACKNOWLEDGMENTS}

This work was financed by General Motors corporation within the framework of the Collaborative Research Lab. (CRL) and is an outcome of a summer internship at GM. The lead author (Vivak Luckhchoura) would like to thank the Powertrain Systems Research Laboratory for their cordial cooperation during the summer internship program. The lead author extends his sincere thanks to Dr Tang-Wei Kuo for giving him the opportunity of an internship at GM R\&D and being supportive during the whole internship period. The authors thank Dr Ronald O. Grover for his assistance during the internship.

(C) Authors 2011

\section{REFERENCES}

1 Wakisaka, Y. and Azetsu, A. Effects of fuel injection rate shaping on combustion and emission formation in intermittent spray. SAE paper 200201-1159, 2002.

2 Seebode, J. Dieselmotorische einspritzratenformung unter dem einfluss von druckmodulation und nadelsitzdrosselung. PhD Thesis, University of Hannover, Germany, 2004.

3 Desantes, J. M., Benajes, J., Molina, S., and González, C. A. The modification of fuel injection rate in heavy-duty diesel engines, part 1: effects on engine performance and emissions. Appl. Therm. Engng., 2004, 24, 2701-2714.

4 Desantes, J. M., Benajes, J., Molina, S., and González, C. A. The modification of fuel injection rate in heavy-duty diesel engines, part 2: effects on combusion. Appl. Therm. Engng., 2004, 24, 27152726.

5 Tanabe, K., Kohketsu, S., and Nakayama, S. Effect of fuel injection rate control on reduction of emissions and fuel consumption in a heavy-duty directinjection diesel engine. SAE paper 2005-01-0907, 2005.
6 Pajot, O., Houille, S., Vidal, F., Dabireau, F., Stegemann, J., Brauer, M., Roelle, T., and Seiffert, A. Injection rate shaping with the twin common rail system: a coupled experimental and modeling investigation. Injection rate shaping with the twin common rail system: a coupled experimental and modeling investigation. In Proceedings of the Diesel Engine Conference, Lyon, France, 31 May-1 June 2006.

7 Kastner, O., Atzler, F., Rotondi, R., and Weigand, A. Evaluation of injection strategies for passenger car diesel engines to meet Euro 6 legislation limits. Conference on Thermo- and Fluid Dynamic Processes in Diesel Engines, 2008.

8 Juneja, H., Ra, Y., and Reitz, R. D. Optimization of injection rate shape using active control of fuel injection. SAE paper 2004-01-0530, 2004.

9 Meyer, S., Krause, A., Krome, D., and Merker, G. P. Ein flexibles piezo-common-rail system mit direktgesteuerter duesennadel. Motortech. Zeil., 2002, 63, 86-93.

10 Stegemann, J. Dieselmotorische einspritzverlaufsformung mit piezoaktuierten experimentaleinspritzsystemen. PhD Thesis, University of Hannover, Germany, 2004.

11 Stegemann, J., Seebode, J., Baltes, J., Baumgarten, C., and Merker, G. P. Influence of throttle effects at the needle seat on the spray characteristics of a multihole injection nozzle. In Proceedings of the ILASS Europe Conference on Liquid atomization and spray systems, Zaragoza, Spain, 9-11 September 2002, pp. 31-36.

12 Stegemann, J., Meyer, S., Rölle, T., and Merker, G. P. Injection system for fully variable control of the shape. Motortech. Zeit., 2004, 65, 13-16.

13 Seebode, J., Merker, G. P., and Lettmann, H. Injection strategies under the influence of pressure modulation and free rate shaping in modern direct injection diesel engines. CIMAC Congress, Kyoto, Japan, 2004.

14 Rottmann, M., Menne, C., Pischinger, S., Luckhchoura, V., and Peters, N. Injection rate shaping investigations on a small bore direct injection diesel engines. SAE paper 2009-01-0850, 2009.

15 Luckhchoura, V., Robert, F.-X., Peters, N., Rottmann, M., and Pischinger, S. Experimental and numerical investigation of injection rate shaping in a small-bore direct-injection diesel engine. In Proceedings of the International Symposium on Towards clean diesel engines, TCDE 2009, 4-5 June 2009, available from, 2009, available from http:// sunsite.informatik.rwth-aachen.de/Publications/ CEUR-WS/Vol-452/ (accessed 27 May 2009).

16 Peters, N. Turbulent combustion, 2000 (Cambridge University Press, Cambridge, UK).

17 Pitsch, H. Modellierung der zündung und schadstoffbildung bei der dieselmotorischen verbrennung mit hilfe eines interaktiven flamelet-modells. PhD Thesis, RWTH Aachen, 1997.

18 Barths, H., Antoni, C., and Peters, N. Threedimensional simulation of pollutant formation in 
a DI diesel engine using multiple interactive flamelets. SAE paper 982459, 1998.

19 Hergart, C. A., Barths, H., and Peters, N. Modeling the combustion in a small-bore diesel engine using a method based on representative interactive flamelets. SAE paper 1999-01-3550, 1999.

20 Hasse, C. and Peters, N. Modeling of ignition mechanisms and pollutant formation in directinjection diesel engines with multiple injections. Int. J. Eng. Rese., 2005, 6, 231-246.

21 Luckhchoura, V., Won, H. W., Sharma, A., Paczko, G., and Peters, N. Investigation of combustion noise development with variation in start of injection using 3-dimensional simulations by applying representative interactive flamelet (RIF) model. SAE paper 2008-01-0950, 2008.

22 Girimaji, S. S. Assumed -PDF model for turbulent mixing: validation and extension to multiple scalar mixing. Combust. Sci. Technol., 1991, 18, 177-196.

23 Ewald, J., Freikamp, F., Paczko, G., Weber, J., Haworth, D. C., and Peters, N. GMTEC developers manual, technical report, Advance Combustion GMBH, 2003.

24 Williams, F. A. Spray combustion and atomization. Phys. Fluids, 1958, 541-545.

25 Crowe, C. T., Sharma, M. P., and Stock, D. E. The particle-source-in cell (psi-cell) model for gasdroplet flows. J. Fluids Engng., 1977, 99, 325-332.

26 Amsden, A. A. KIVA-3: A KIVA program with block-structured mesh for complex geometries, technical report LA-12503-MS, Los Alamos National Laboratories, 1993.

27 Beale, J. C. and Reitz, R. D. Modeling spray atomization with the Kelvin-Helmholtz/Rayleigh-Taylor hybrid model. Atomization Sprays, 1999, 9, 623-650.

28 Antoni, C. Untersuchung des verbrennungsvorgangs im direkteinspritzenden dieselmotor mit zyklusaufgelöster emissionsspektroskopie. PhD Thesis, Rheinisch-Westphälische Technische Hochschule Aachen, 1998.

29 Barths, H. Simulation of diesel engine and gas turbine combustion using multiple flamelets with detailed chemistry. PhD Thesis, RWTH Aachen, 2001.

30 Bollig, M. Berechnung laminarer kohlenwasserstofflammen in hinblick auf die stickoxidbildung in verbrennungsmotoren. PhD Thesis, RWTH Aachen, 1998.

31 Frenklach, M. and Harris, S. J. Aerosol dynamics modeling using the method of moments. J. Collord Interface Sci., 1987, 118, 252-261.

32 Mauss, F. Entwicklung eines kinetischen modells der ruß bildung mit schneller polymerisation. $\mathrm{PhD}$ Thesis, RWTH Aachen, 1997.

33 Eng, J. A. Characterization of pressure waves in HCCI combustion. SAE paper 2002-01-2859, 2002.

34 Diwakar, R. and Singh, S. $\mathrm{NO}_{x}$ and soot reduction in diesel engine premixed charge compression ignition combustion: a computational investigation. Int. J. Eng. Res. 2008, 9(3), 195-214. DOI: 10.1243/ 14680874JER00308. 